\title{
Análisis del capital social y su implicancia en el desarrollo de diversas estructuras económicas
}

\author{
Analysis of social capital and its involvement in the development of \\ various economic structures
}

\section{Análise do capital social e seu implicação no desenvolvimento de várias estruturas económicas}

\author{
Manuel Kamichi \\ Universidad Nacional Mayor de San Marcos \\ manuel.kamichi@unmsm.edu.pe \\ https://orcid.org/0000-0002-3222-3319
}

\begin{abstract}
RESUMEN
El presente artículo tiene como objetivo principal analizar qué es el capital social y las distintas estructuras económicas que se pueden desarrollar a partir de la presencia de este tipo de capital; para ello, primero se ha recurrido a una investigación conceptual del término y sus características principales; después, se ha recabado diversos modelos de estructuras económicas que se construyeron por medio del capital social. Con este fin, la metodología que se ha hecho uso es la de la revisión de 126 fuentes secundarias. A través de la investigación se descubre que el capital social es utilizado como un medio para desarrollar diversas formas de estructuras económicas en diferentes espacios y tiempos como cooperativas, modelos autogestionados, organizaciones civiles y redes de relaciones inter-institucionales en múltiples contextos en donde todos tienen en común la presencia de este tipo de capital. En los modelos descritos se caracteriza la presencia de lazos sociales fuertes basados en valores como la solidaridad, la cooperación, la ayuda mutua y la confianza.
\end{abstract}

\begin{abstract}
SUMMARY
The main objective of this article is to analyse what is the share capital and the different economic structures that can be developed from the presence of this type of capital; to this end, conceptual research on the term and its main characteristics has first been used; Afterwards, various models of economic structures have been gathered that were built through social capital. To this end, the methodology that has been used is the review of 126 secondary sources. Through research it is discovered that social capital is used to develop various forms of economic structures in different spaces and times such as cooperatives, self-managed models, civil organizations and networks of interinstitutional relations in multiple contexts where everyone has in common the presence of this type of capital. The models described are characterized by the presence of strong social ties based on values such as solidarity, cooperation, mutual assistance and trust.
\end{abstract}

Kamichi, M. (2021). Análisis del capital social y su implicancia en el desarrollo de diversas estructuras económicas. Espiral, revista de geografías y ciencias sociales, 3(5), 53-84. https://dx.doi.org/10.15381/espiral.v3i5.18780 


\section{RESUMO}

O objetivo principal deste artigo é analisar o que é capital social e as diferentes estruturas econômicas que podem ser desenvolvidas a partir da presença desse tipo de capital; para isso, primeiramente foi utilizada uma investigação conceitual do termo e suas principais características; posteriormente, vários modelos de estruturas econômicas que foram construídas por meio do capital social foram coletados. Para tanto, a metodologia utilizada é a revisão de 126 fontes secundárias. Através desta pesquisa, descobre-se que o capital social é utilizado como meio para desenvolver diferentes formas de estruturas econômicas em diferentes espaços e tempos, tais como cooperativas, modelos autogestionários, organizações civis e redes de relações interinstitucionais em múltiplos contextos onde todos eles existem e compartilham a presença desse tipo de capital. Nos modelos descritos é caracterizada a presença de fortes laços sociais baseados em valores como a solidariedade, a cooperação, a ajuda mútua e a confiança.

PALABRAS CLAVES: capital social; estructura económica; cooperación económica; autogestión económica.

KEYWORDS: social capital; economic structure; economic cooperation; self-management economy.

PALAVRAS CHAVES: capital social; estrutura econômica; cooperação; autogestão.

\section{Introducción}

Se ha demostrado a partir de diversas investigaciones la limitación de analizar el crecimiento económico considerando exclusivamente los recursos disponibles (Rusque, 2005), por lo que el economista Joseph Stiglitz menciona la necesidad de renovar todo lo que se acepta como verdad en la economía de desarrollo (Stiglitz J. , 1998).

Tradicionalmente se ha medido la riqueza de una economía; es decir, los recursos que pueden ser usados para la producción, a través del capital físico (que es tangible y que fue creado por seres humanos -maquinarias, ordenadores, carros, etc.-), trabajo (intervención humana en la producción -trabajadores-) y tierra (recursos naturales -terrenos cultivables, minerales, petróleo, etc.-) $[\mathrm{Y}=\mathrm{F}(\mathrm{K}, \mathrm{L}, \mathrm{t})]$ (Gil-Lacruz \& GilLacruz, 2006), también considerando solamente el trabajo y el capital físico $[Q=f(K$, L)] o en el Cobb-Douglas, donde se considera capital físico, trabajo y tecnología (uso de conocimientos y técnicas), o en su versión donde se incluye recursos naturales ( $Q$ $=K^{a} L^{b} R^{c}$ tal que: a $\quad$ b $\left.\quad c=1\right)$ (Urbina, 2015). Por otro lado se tiene dentro del modelo keynesiano, es decir la teoría económica que se basa en los postulados del economista John Maynard Keynes, el teorema Harrod-Domar $[\dot{K} / \mathrm{K}=\mathrm{s} / \mathrm{v}]$, que considera la tasa de crecimiento del capital $(\dot{K})$, el capital (K), la tasa promedio de ahorro (s) y la relación entre el capital y el producto (v) (Meier \& Stiglitz, 2002). Cabe señalar que el capital es el conjunto de recursos y poderes utilizables (Huber \& Lamas, 2017) y que se invierten o que pueden ser invertidos para obtener beneficios (García-Valdecasas, 2011).

Pero estos modelos comienzan a ser cuestionados al darse cuenta que se requerían factores humanos, por lo que se comenzó a comprender que el desarrollo económico es multifacético (Mavares, Díaz, Colina, Lombardi , \& Prieto, 1999). Ante esto es que en las últimas décadas ha comenzado a surgir corrientes de pensamientos donde se incluye al capital social como uno de los componentes para el desarrollo (Rodríguez, 2012) y rápidamente fue incorporado como un indicador de desarrollo (Palma, 2015). Se puede decir entonces, que el capital social surge ante los fracasos de la concepción del desarrollo por las limitaciones economicistas (Jiménez \& Piña, 2011).

A partir de las investigaciones relacionadas sobre el capital social en el desarrollo económico, principalmente hechas en el siglo XX, se puede corroborar la importancia de este capital para conseguir el crecimiento económico (Portela \& Neira, 2002). Pero este progreso implica estructuras económicas particulares debido a la presencia del 
capital social. Es en ese sentido, que el artículo tiene como objetivos el desarrollo teórico del concepto del capital social, la descripción de sus características y de su implicancia en el desarrollo de distintas estructuras económicas. Para ello, se ha utilizado la revisión de fuentes secundarias como metodología investigativa, por lo que se ha analizado 126 fuentes en total que están en las tres secciones del presente trabajo que muestran los resultados: "CAPITAL SOCIAL", "CAPITAL SOCIAL EN EL DESARROLLO ECONÓMICO” y “ESTRUCTURAS ECONÓMICAS BASADAS EN EL CAPITAL SOCIAL".

\section{Metodología}

El presente trabajo es una investigación bibliográfica, lo que significa, que el estudio se basa en la revisión de distintos textos relacionados a la temática y que fueron hechos por distintos autores (Kogan, 2011), por lo que todas las fuentes son secundarias. Es de carácter cualitativo y con la información recabada se ha hecho un análisis descriptivo.

Sobre esto último, el análisis descriptivo, se debe señalar que el análisis se ha realizado al descomponer la información de las fuentes revisadas con el fin de evaluar cada uno de los componentes y utilizar las partes que se ha considerado como relevantes para la presente investigación (Noguero, 2002). Después de ello se ha apelado a la descripción, es decir, se expone las características principales de la información provista por la fuente (Malhotra, 1997).

Como en todas la investigaciones que usan como metodología investigativa la revisión bibliográfica se ha realizado una selección interesada de los estudios (Napoli, 2018); para ello, se ha utilizado criterios, que consistió en el uso de las fuentes que abarcaban algunos de los siguientes temas: a) el origen del capital social, b) su desarrollo conceptual, c) sus principales características, d) su relación con la economía, e) la existencia de casos en donde muestre este tipo de capital en el desarrollo económico y f) donde se describa estructuras económicas basadas en el capital social.

En total, se han utilizado 126 fuentes y se crearon tres secciones de la investigación con sus respectivos subíndices: "Capital Social" (subíndices: Uso del capital social, Conceptualización de capital social, Características del capital social y Conceptos de los términos relacionados al capital social), "Capital Social en el Desarrollo Económico" (sin subíndices) y "Estructuras Económicas Basadas en el Capital Social" (subíndices: Capital social en la cultura andina, Capital social en empresas cooperativas de América Latina, Capital social en empresas cooperativas de Europa, Capital social en empresas que no son cooperativas, la era de la Investigación y el Desarrollo (I+D), El capital social en la cooperación inter-institucional para el desarrollo de la I+D, Capital social intra-empresarial, Capital social en la autogestión económica, Capital social laboral, Capital social financiero y Voluntariado).

De esas 126 fuentes, 74 son artículos académicos; 44 son libros, 2 informes, 1 archivo digital, 1 entrevista, 2 tesis, 1 página web y 1 acta de conferencia. Para la búsqueda de las fuentes se recurrió a distintas bases de datos como Redalyc, Dialnet, Google Académico, entre otros. Pero también se apeló a bibliotecas para los libros físicos. Con ello, se seleccionó las fuentes que se consideró como necesarias para el desarrollo de este trabajo.

\section{CAPITAL SOCIAL}

\section{Uso del capital social}

Se encuentran ejemplos de lo que es el capital social; es decir, su existencia desde varios años antes que su propia conceptualización (el término recién se comienza 
a definir a finales de los ochenta), por ejemplo, con la existencia de asociaciones cooperativas en el antiguo Egipto, en los fenicios y Roma (Miranda, 2011); también se muestra en los filósofos de la Antigua Grecia como en Platón con su Utopía Platónica, basada en la idea de la colectivización (Suzzarini, 2010); también está en la Ilustración con el filósofo Baruch Spinoza con su idea de autogobierno (Hudson, 2010).

Pero donde recién se liga a una doctrina, específicamente al socialismo, es con los socialistas utópicos (siglo XVIII y XIX) con sus propuestas del trabajo comunitario, basado en la igualdad, la solidaridad, principios morales (Rodríguez \& Ciolli, 2011), y en varios casos en la asociación cooperativista (Guerra, 2014), que coinciden en mucho con las propuestas anarquistas como las de Proudhon y Bakunin (Vicente, 2015).

Además, también está Tocqueville (1986), cuando en el siglo XIX resalta las relaciones asociativas de los estadounidenses frente a los franceses, que traía como consecuencia un mejor desenvolvimiento de la democracia. También están los aportes de los teóricos sociales clásicos; Marx, con las relaciones proletarias, dicho autor se ha referido en varias ocasiones a los beneficios producto de las relaciones sociales del proletariado, por ejemplo, al indicar el aumento del rendimiento del obrero gracias a la cooperación entre ellos (Marx, 1994); Durkheim (1993), cuando resalta las características de la organización colectiva, como en la solidaridad -tanto mecánica como orgánica- y el consenso moral, esa conscience collective, en la división del trabajo; y por último, Weber, con sus estudios de las organizaciones de las sociedades religiosas (Pisani \& Micheletti, 2018).

Pero la primera persona en utilizar el término fue Hanifan, cuando se refirió a la existencia del capital social gracias a la cadena de relaciones y que trae como beneficio la posibilidad de satisfacer necesidades y mejorar las condiciones de vida en la comunidad (Hanifan, 1916).

En resumen, las características del capital social ya existían, tanto a nivel empírico (como en las cooperativas por ejemplo) como a nivel teórico (en propuestas como en la Utopía Platónica), antes de que el término fuera conceptualizado, todas ellas coincidiendo en la unión entre las personas para poder lograr objetivos comunes.

\section{Conceptualización de capital social}

En lo que respecta a conceptualizar el término, los pioneros surgen a finales de los ochenta y son Bourdieu, Putnam y Coleman.

Bourdieu indica que el capital social son los recursos que permiten poseer redes de relaciones que están medianamente institucionalizados donde existe un mutuo reconocimiento, estas relaciones sociales, que es el capital social de la persona, puede ser usado para tener la ventaja de obtener recursos frente a lo que no lo poseen (Bourdieu, 1986) (Bourdieu, 1985). Es decir, el capital social se trata de la relación social y el beneficio obtenido gracias a esta (Bourdieu, 1989).

Putnam, Leonardi y Nanetti señalan que el capital social son los "aspectos de la organización social tales como confianza, normas y redes, que pueden mejorar la eficiencia de una sociedad al facilitar la acción coordinada" (Putnam, Leonardi, \& Nanetti, 1993, pág. 167).

Para Coleman el capital social es una estructura social donde existe un activo, como si fuera un factor productivo, para que se pueda beneficiar quien lo posea a través de la relación con los demás, siempre circunscritos en normas y valores compartidos por el grupo. Es decir, el capital social es una ventaja producto de la estructura social que lo tienen todas personas inmersas en las redes sociales, además de considerarlo como acumulable si es que se usa y devaluado si es que no se renueva (Coleman, 1990) (Coleman, 1994). 
Posterior a ellos, aparecieron varios autores en conceptualizar el término, por ejemplo, según Woolcock y Narayan el capital social son "las normas y redes que facultan a la gente para actuar colectivamente" (Woolcock \& Narayan, 2000, pág. 226), además, Huerta agrega que "deben producir beneficios" (Huerta, 2017, pág. 95).

Rodríguez también identifica el capital social con normas y organizaciones sociales, solamente que según la autora, estos "facilitan la cooperación de los agentes en la persecución de un beneficio común y tienen un impacto en la eficacia y eficiencia de una comunidad" (Rodríguez P. , 2012, pág. 264). Para Duston el capital social "es un recurso (o vía de acceso a recursos) que, en combinación con otros factores, permite lograr beneficios para los que lo poseen. Por otro lado, esta forma específica de capital reside en las relaciones sociales" (Durston, 2000, págs. 7-8).

Para Fukuyama, el capital social "es el crisol de la confianza, y si bien su origen se encuentra en las raíces culturales de cada sociedad, constituye un elemento importante en la salud económica" (Fukuyama, 1996, pág. 33).

La sociología económica conceptualizó al capital social como el conjunto de personas, sus interacciones a través de redes sociales y las instituciones por medio de las normas que permiten la acción colectiva para obtener beneficios (Morales, 2002).

En síntesis, se puede observar que el capital social se trata de un recurso intangible que posibilita conseguir beneficios gracias a las relaciones sociales (Jiménez \& Piña, 2011). En donde esas relaciones son redes conformadas, principalmente, por la confianza, normas y reciprocidad (Ostrom \& Ahn, 2003). En lo que respecta a los beneficios gracias al capital social, uno de ellos es el económico (Portes, 1998), que es en lo que se centra la presente investigación.

\section{Características del capital social}

Las condiciones para la existencia del capital social son las redes, recursos, intercambio, normas y valores aceptados y respetados en el grupo; y por último, sanciones y recompensas (Halpern, 2005), en donde todas ellas se enmarcan dentro de cuatro visiones distintas, el primero es el comunitario (autogestión local), redes (la relación intracomunitaria e intercomunitaria), institucional (organización) y la sinérgica (redes) (Capdevielle, 2014).

Además, son tres tipos de capital social, el bonding (relaciones dentro del mismo grupo), el bridgin (las relaciones entre personas de distintos grupos) y el linking (la vinculación entre la sociedad civil con las instituciones públicas) (Frediani, 2011).

Se puede observar que el capital social depende de las características que se dan en los dos actores claves, las personas y las estructuras. Como lo indicó Uphoff, uno es el capital social cognitivo - donde se encuentra la subjetividad de los sujetos, sus valores, pensamientos, etc. - y el otro es el capital social estructural - el término se refiere a las organizaciones e instituciones - (Rusque, 2005).

Es la perspectiva del estructural funcionalismo o también conocido como estructuralismo funcionalista que desarrolla Giddens, que se trata de la reconceptualización de la estructura en dualidad, que es la mirada de abarcar tanto a las instituciones -que sería lo objetivo-, como a los individuos -que es lo subjetivo(Giddens, 2006), en donde el marco institucional influye en el comportamiento de los sujetos, pero al mismo tiempo, el comportamiento de esos sujetos influye en ese marco (Rodríguez, 2012).

\section{Conceptos de los términos relacionados al capital social}

Según North, las instituciones son los límites que se conciben en la interacción humana, está formada por valores y normas que posibilitan la confianza entre los 
sujetos (North, 1990). Pueden ser formales (leyes, reglamentos, contratos, etc.) o informales (costumbres, moral y normas) (Vargas, 2002).

"Confiar significa pensar que cuando ofrecemos a otra persona una oportunidad, ella no actuará de manera que nos ocasione un daño" (Cornejo, 2005, pág. 94); mientras que las redes sociales es cuando hay un "determinado número de actores vinculados entre ellos mediante relaciones interpersonales" (Huber \& Lamas, 2017, pág. 98); la cooperación es la actividad complementaria de un conjunto de personas que comparten un mismo objetivo de una actividad en común; y la asociatividad es cuando se relacionan las personas unas con otras formando asociaciones (Lobo \& Eva, 2011).

El desarrollo es un proceso de crecimiento y/o cambio para lograr los objetivos de satisfacer necesidades (Lelé, 1991), mientras que la economía es el sistema que involucra a todo el proceso y agentes para generar bienes y servicios (Coraggio, 2016). Ante ello, el desarrollo económico hace referencia al aumento en los procesos y agentes para la generación de bienes y servicios, que es la definición que se utilizará cuando se haga referencia tanto a desarrollo como a crecimiento económico.

\section{CAPITAL SOCIAL EN EL DESARROLLO ECONÓMICO}

En lo que respecta al crecimiento económico, el capital social es crucial de muchas maneras para alcanzarlo, fundamentalmente porque posibilita acciones en conjunto (Bazan \& Schmitz, 1997), por ejemplo, en el intercambio de recursos, de aprendizajes, en innovación, entre otros factores claves para el logro económico (Adler \& Kwon, 2002).

Woolcock resalta los siguientes elementos como claves del capital social para el desarrollo económico: fuerte cohesión dentro de la sociedad, conexión con el resto del mundo, un Estado autónomo, caracterizado por una integridad organizativa y que tenga sinergia con la sociedad (Woolcock M. , 1998).

Según Kuznets, la principal ventaja que tienen los países pequeños que poseen un alto desarrollo económico (como los países nórdicos, Suiza, Bélgica, etc.) se debe a la fuerte interacción que existe en sus poblaciones, lo que genera fuertes vínculos entre ellos y sus organizaciones, lo que constituye su principal ventaja comparativa (Kuznets, 1960).

La fuerte correlación entre capital social y desarrollo económico es algo que se comprueba en la investigación de Knack y Keefer, los cuales descubren, a partir de una muestra de 29 países (17 de Europa -considerando a Turquía en este continente-, 1 de Oceanía, 6 de América, 3 de Asia y 2 de África), que la confianza, el cumplimiento de normas cívicas y la participación activa en asociaciones tienen una fuerte relación con el crecimiento económico y renta per cápita (Knack \& Keefer , 1997).

A través de un estudio econométrico basados en las encuestas hechas por World Value Surveys para Europa se demuestra que existe una relación positiva y de significancia entre las variables que forman el capital social (en este caso es el nivel de confianza y la pertenencia a algún grupo que realice voluntariado) con crecimiento económico (Portela \& Neira, 2002).

Enelestudio sobrelasregiones de Italia dePutnam, Leonardi y Nanetti,los mencionados autores señalan que la región del norte presenta un mayor crecimiento económico gracias al capital social, principalmente por la confianza, normas, comportamientos cívicos y la capacidad asociativa. En donde resaltan la región como una comunidad cívica que resulta de un proceso histórico, preservando las características asociativas por medio del capital social (Putnam, Leonardi, \& Nanetti, 1993). 
Cabe señalar que esta región italiana tiene una fuerte tradición de solidaridad y participación social gracias a las acciones de la Resistencia antifascista durante la Segunda Guerra Mundial, que estaban agrupados principalmente en el norte del país, en donde las izquierdas dirigieron estos movimientos; por lo que ganaron prestigio y lograron penetrar en la población generando un desplazamiento político de los ciudadanos hacia esta orientación, con lo que obtuvieron un protagonismo como nunca antes, convirtiéndose en partidos de masas (Marín, 2014). Gracias a ello pudieron implantar su ética concordante al capital social, -las ya mencionadas solidaridad y participación social-.

Una de las estrategias que aplican diversos agentes económicos en la actualidad es formar redes para aumentar su competitividad dentro de este mercado mundial (Cornejo, 2005), por lo que el capital social es vital porque facilita la cooperación en ellos (Das, 2004).

En Tanzania, las familias pobres que poseían mayor capital social - basado en la participación en organizaciones sociales - obtienen mayores ingresos económicos gracias a esta, por ejemplo, al conseguir información sobre nuevos métodos de producción agrícola, conocimientos para alcanzar ciertos recursos, producción colectiva, etc. (Narayan \& Pritchett, 1997).

Con todo lo descrito se puede observar que sí existe evidencia de que el capital social, basado en relaciones con fuertes vínculos entre ellos y sus organizaciones que se caracterizan por la existencia de confianza, el cumplimiento de normas cívicas y la participación en diversas organizaciones, puede aportar en el desarrollo económico independientemente del país en donde uno se encuentre; es decir, es universal. Esto se puede explicar porque desde los orígenes del ser humano este vivía en grupos para poder sobrevivir (Kröpotkin, 2005).

\section{ESTRUCTURAS ECONÓMICAS BASADAS EN EL CAPITAL SOCIAL}

\section{Capital social en la cultura andina}

La cultura, definida como la práctica y el imaginario de la vida en común (Rey, 2007), se encuentra en todos los componentes básicos que conforman el capital social porque es un factor decisivo para poder lograr la cohesión social. Por ejemplo, históricamente, los campesinos andinos han gozado de capital social al adoptar los valores culturales indígenas basados en la cooperación, trabajo en común y solidaridad (Kliksberg, 1999).

Esto ha ocurrido desde tiempos anteriores a la era cristiana en Sudamérica con el modelo socio-económico llamado Racionalidad Andina por el economista Dante A. Urbina, en el cual se caracteriza por tratar de mantener una relación interpersonal basada en la reciprocidad, la cooperación, la tierra comunal y el trabajo en común. En donde el campesino minimiza riesgos racionalizando sus recursos al trabajar colectivamente y en donde se labora en armonía no solamente entre unos con otros en comunidad, sino también en equilibrio con el medio ambiente (Urbina, 2015).

Mariátegui encontró en la organización indígena del trabajo su ideal de modelo económico al encontrase con la socialización de los medios de producción a través de la colectivización de la tierra, en donde se prevalecía relaciones comunitarias basadas en la solidaridad y la cooperación, en lo que él denominó como "socialismo indoamericano", y que no se limitaba solamente al trabajo, sino en todos los aspectos de sus vidas (Marañón-Pimentel, 2012).

Estas características se extienden más allá de Sudamérica, por ejemplo en Chiapas (México), los indígenas hacen uso de prácticas basadas en la reciprocidad, la solidaridad u otras formas de asociación que se apoyan en los lazos sociales para el 
aspecto económico, por ejemplo, el intercambio de alimentos a cambio de trabajo a futuro, el trueque, entre otras formas (Vergara-Camus, 2011).

Como se puede observar, la cultura indígena se caracteriza por la cooperación, el trabajo conjunto y la solidaridad que forman el capital social para ellos y que se ve evidenciado en la agricultura.

\section{Capital social en empresas cooperativas de América Latina}

En las empresas cooperativas la propiedad es social (Iglesias, 2007) y tiene como base el cooperativismo como principal valor, por lo que se resalta el trabajo en común (Carrau, 2017). Las cooperativas son una de las tantas maneras que existen dentro de los modelos de autogestión, y hay de tres tipos: cooperativas de producción (producen y comercializan bienes y servicios), cooperativas de consumo (sirven para comprar bienes y servicios) y las cooperativas mixtas (cumplen la función de las dos anteriores a la vez) (Cruz \& Piñeiro, 2011). Con los siguientes casos recogidos se pretende mostrar ejemplos de la implicancia del capital social en la estructura de las empresas cooperativas de América Latina.

La asociación de productoras "Manos del Uruguay" se conforma por cooperativas e inició en 1968 con el objetivo de promover la comercialización de los productos artesanales hechos por las mujeres de dicho país a través de la producción, venta, capacitación, cooperativismo y administración democrática por medio de las Asambleas. A nivel económico trajo como consecuencia que se introdujeran tecnologías que mejoraron la calidad de los productos, lo que generó que ahora puedan exportar más de la mitad de toda su producción (Coraggio, 1999). El capital social en este caso se manifiesta en la ayuda existente entre las cooperativas que conforman la asociación de productoras y en la participación democrática de las integrantes para la toma de decisiones.

En 1968 se aprueba la Ley de Viviendas en Uruguay (Ley No. 13.728), con lo cual se desarrolla un sistema de construcción de hogares a través de dos cooperativas, ahorro previo (que procede de un ahorro grupal para el aporte del $15 \%$ del valor de la vivienda) y el de ayuda mutua (en donde el aporte es por mano de obra). Así es que surgen las Cooperativas de Vivienda Ayuda Mutua (agrupadas en la Federación Uruguaya de Cooperativas de Vivienda por Ayuda Mutua -FUCVAM-) (Nahoum, 1984) (Machado, 2020).

En estas, el trabajo se basa en la autoconstrucción por parte de los propios miembros gracias a los préstamos obtenidos por dicha Ley y con asesoramiento técnico externo. No existen intermediarios y prima la autogestión y la solidaridad. Entre los beneficios se encuentran que los costos son bajos (entre 30 a 35 \% más barato que los del mercado), lo construido calza con las necesidades de los destinatarios (al estar ellos involucrados en la obra) y existe una valorización de espacios comunes en la comunidad (calles, plazas y sendas) (Nahoum, 1984).

Hasta el momento, gracias a la FUCVAM, se han construido 18.288 viviendas, 1.508 están en obra y existen 2.932 familias en trámite para el préstamo (Machado, 2020). Entre las razones del éxito, Luis del Castillo señala que se debe a la autogestión, la ayuda mutua, la cohesión y los valores como la solidaridad que han permitido que el modelo tenga éxito (Castillo, 2011). Esto último (la autogestión, ayuda mutua, cohesión y solidaridad) sería el capital social.

La Cooperativa Acopagro (San Martín - Perú) que inició labores en 1992 (desde 1997 se llama Cooperativa Agraria Cacaotera ACOPAGRO) y que tenía una producción de 50 toneladas y estaba conformada por 27 miembros, fue beneficiada del Programa de las Naciones Unidas, que los impulsó y financió integralmente en el cultivo de cacao, en donde se les dio asistencia técnico-productiva, crédito para acopio, comercialización y 
fortalecimiento organizacional. Gracias a ello, en la actualidad producen más de 3000 toneladas y cuentan con más de 2500 socios, además de haber sido la pionera en la exportación de granos de cacao especiales del país (Enrico, 2014). Aquí se puede ver el capital social en la cooperación inter-institucional del Programa de las Naciones Unidas a Acopagro, además del intra-institucional en la propia cooperativa por medio de la intervención del Programa en su fortalecimiento de la organización.

En Chiapas - México, las familias zapatistas y el Ejército Zapatista de Liberación Nacional (EZLN), que tienen una organización social en territorios autónomos, han desarrollado proyectos económicos basados en el capital social desde 1994 como gallineros comunitarios, intercambios de conocimientos sobre agroecología, hornos colectivos, sastrerías comunitarias, cooperativas como el de las tejedoras, entre otros (Vergara-Camus, 2016). El capital social en este caso reside en el apoyo que tienen los miembros para ayudarse mutuamente.

\section{Capital social en empresas cooperativas de Europa}

Es por la Revolución Industrial que en Europa se crean cooperativas con el fin de combatir las condiciones de vida que tenían los propios trabajadores en aquella época (Gambina \& Roffinelli , 2011). Por ejemplo, en 1760 en Inglaterra se creó una cooperativa por parte de molineros para procesar el trigo y vender harina a precios muy bajos, con el objetivo de romper con el monopolio de venta de harina que existía hasta ese momento (Cruz \& Piñeiro, 2011). Los pioneros en proponer las cooperativas como principal forma de organización productiva fueron los socialistas utópicos, estos querían desarrollar organizaciones sociales basadas en la justicia social (Gambina \& Roffinelli , 2011).

En este grupo están Charles Fourier, con su idea de crear asociaciones de personas que vivirían en comunidades que él los denominó como falansterios y que tendría como característica principal la redistribución económica y una organización de la división del trabajo que evitaría la competencia entre ellos; Robert Owen, con su pensamiento de que las cooperativas llevarían a la cooperación integral de los trabajadores; y por último, Charles Gide, que apuntaba a las cooperativas como forma de incentivar la solidaridad y la soberanía del consumidor a través de cooperativas de consumo (Hudson, 2010).

Por ejemplo, Owen creó varias cooperativas (New Harmony, London Co-operative Society, Brighton Co-operative Society, British Co-operator, etc.) pero una de sus mayores innovaciones se dio en 1832 con el establecimiento de la "Bolsa nacional de cambio equitativo del trabajo" que se encargaba de emitir "billetes de trabajo" que mostraban los costos y el tiempo invertido en la producción soslayando las relaciones de trabajo existentes en la producción, pero esta iniciativa fue destruida en 1834 por una campaña violenta de los burgueses de la época (Miranda, 2011).

En 1844 en Inglaterra 28 obreros del sector textil que habían conformado una cooperativa de consumo en Rochdale (Inglaterra) crearon la sociedad Equitativa de los Pioneros de Rochdale y que generarían los principios pioneros para la gestión cooperativa, entre las cuales destaca el control democrático (Hudson, 2010). La cooperativa compraba bienes en grandes cantidades para después venderlos a sus integrantes a un precio solamente un poco mayor al costo de compra (Cruz \& Piñeiro, 2011).

La empresa Scott Bader Co. Ltd., es fundada por Ernest Bader en Inglaterra en 1920, ya en 1951 contaba con 161 empleados y tenía beneficios netos por arriba de los 72.000 libras esterlinas anualmente, en ese mismo año decide darle el $90 \%$ de la propiedad de la empresa a la comunidad de Scott Bader y el otro $10 \%$ en 1963, todo bajo el cumplimiento de ciertas condiciones para el manejo, de los cuales destaca la baja 
desigualdad salarial, la administración por la propia comunidad y una redistribución de una parte de los beneficios para fines caritativos. Entre las consecuencias económicas estuvo el hecho de que para 1971 los beneficios netos aumentaron, logrando alcanzar el promedio de 300.000 libras esterlinas al año, se creció en número de trabajadores llegando a 379 y se crearon nuevas empresas. Todo esto comprobó lo dicho por Ernest Bader al señalar que la propiedad en común posee ventajas únicas (Schumacher, 1978).

Coop es una cooperativa en Suiza (fue fundada en 1890 como USC y recién en 1969 como Coop Suiza) que ha formado una cadena de supermercados que se ubica entre las empresas minoristas más grandes del país en la actualidad, lo mismo ocurre con Co-op en el Reino Unido. Entre los beneficios de ser cooperativas se encuentra el hecho de que al comprar en forma de cooperativa a los proveedores los costos son menores, por lo que pueden vender sus productos a bajos precios (Chang H.-J., 2015).

La cooperativa más grande del mundo es Mondragón, que nace en País Vasco a mediados del siglo XX. Está conformada por más de 124 cooperativas que se dedican al rubro de las finanzas, industria, distribución y conocimiento. Cuentan con más de 80.000 miembros (aproximadamente un tercio son socios de cooperativas, los otros trabajan de manera tercerizada) y utilizan una red de intercooperación basada en la solidaridad, donde todos se ayudan mutuamente -por ejemplo, si una cooperativa está en crisis pueden trasladar a cierta cantidad de sus miembros a que vayan a otra cooperativa que esté en mejor situación-. Todo esto va a acompañado de un desarrollo económico exponencial que se visualiza en sus ventas, las cuales superan los 11.000 millones de euros anuales (Mondragón, 2019) (Altuna, Loyola , \& Pagalday, 2011) (Piñeiro, 2011).

A nivel interno en Mondragón cada cooperativa está gestionada de manera democrática por sus propios miembros, hay una alta distribución económica, y en lo que respecta hacia afuera, tienen un fuerte compromiso social al donar $10 \%$ de sus utilidades netas para beneficiar a la sociedad, tanto en lugares cercanos a sus centros de producción como en los lejanos (Altuna, Loyola , \& Pagalday, 2011) (Piñeiro, 2011).

Los tres órganos principales de la cooperativa Mondragón son: el Congreso Cooperativo, que da las pautas y criterios generales para todos; la Comisión Permanente del Congreso, que se dedica principalmente a promover la eficiencia empresarial y a actuar sobre las decisiones del Congreso; y por último, está el Consejo General, que se encarga de dirigir y coordinar las cooperativas (como ejemplo, definir estrategias y objetivos) (Altuna, Loyola , \& Pagalday, 2011).

Se puede evidenciar con esto que las cooperativas, independientemente de dónde sean -se han mostrado casos en Uruguay, Perú, México, Inglaterra, Suiza y España-, debido a su estructura se deben basar en el cooperativismo (capital social), y esto les permite obtener ventajas económicas y sociales.

\section{Capital social en empresas que no son cooperativas}

Ojeda, Mul, López y Jiménez (2010) estudiaron la microempresa rural de Koolel Lab, ubicado en la ciudad de Campeche (México), y que se dedica al rubro alimenticio, específicamente producen y venden miel y subproductos (como jabones, cremas y gotas para los ojos, todos estos subproductos son elaborados teniendo a la miel como uno de sus ingredientes)

En lo que respecta a su organización, todas las decisiones se toman de manera democrática a través de la participación de las socias por medio de votación, en donde previamente se provee de toda la información necesaria sobre el asunto en cuestión. Además, las relaciones interpersonales son basadas en la confianza, honestidad en la información, el cumplimiento total de las normas y la generación 
de contactos externos, que forman la esencia de su capital social (Ojeda, Mul, López , \& Jiménez, 2010).

La investigación concluye que el capital social les permitió acceder a información relevante a bajo costo y confiable del mercado, mejorar su comercialización a través de mayores puntos de ventas, obtener apoyos tanto en lo económico como en recibir capacitaciones, mejorar su administración, incorporar nuevas maquinarias y tecnologías, innovar al crear nuevos productos, aumentar sus ventas; y por ende, sus ganancias (Ojeda, Mul, López , \& Jiménez, 2010).

Otro caso se da en la comunidad San Pedro Sacatepéquez en Guatemala, como alternativa a la economía agrícola, han emprendido desde finales de los cincuenta el comercio de prendas de vestir, en donde su desarrollo se ha caracterizado principalmente por las redes de reciprocidad, de hecho el primer taller de confección de ropa sirvió como una escuela para expandir el aprendizaje del rubro en toda la comunidad (Pérez, 1996).

Los emprendedores que se dedican a este sector aprendieron este oficio y lograron la instalación de sus talleres gracias a la ayuda proporcionada por sus familiares y amigos, además que para la subcontratación también usaron las redes de sus familiares para conseguir los contactos (Pérez, 1996).

El estudio de Lyon en Ghana comprueba que para tener una exitosa microempresa agrícola es vital el capital social, en este caso basado en las redes sociales, porque generan confianza (Lyon, 2000).

Gamarra, que es un emporio comercial donde se encuentran varias empresas del rubro textil en el distrito de La Victoria, en Lima - Perú, se forma por puneños que compraron terrenos y construyeron galerías gracias al apoyo de sus paisanos de las comunidades de origen, que solamente por comida y alojamiento les proveían de mano de obra. Esta cooperación entre miembros (aquí está el capital social) se extendió al ámbito productivo, en donde entre familiares y paisanos se contratan para trabajar, realizan intercambios de información, préstamos de maquinarias, etc. (Cornejo, 2005).

En los noventa migraron integrantes de la comunidad de Ichu (Puno) a la avenida Caquetá, ubicado en el distrito de San Martín de Porres, en Lima - Perú, y comenzaron a construir sus negocios, a pesar de que cada empresa es independiente uno de otro utilizan la cooperación entre ellos (capital social) para la acumulación de capital (Huber \& Lamas, 2017).

Como se puede observar con los casos descritos en México, Guatemala, Ghana y Perú el capital social beneficia a las empresas en factores relevantes para la producción, entre los que se encuentran obtención de información, capital, mejoramiento de la producción, entre otros.

\section{La era de la Investigación y el Desarrollo (I+D)}

En los setenta, las empresas se enfrentan a una nueva realidad, surgen nuevas tecnologías, diversidad cultural, internacionalización (López, Martín , \& Romero, 2007), empiezan las políticas neoliberales en el mundo como en las dictaduras de Argentina, Chile, Uruguay y Brasil (Klein, 2010). Todo esto produce que las empresas tengan que adaptarse constantemente para poder enfrentar esas nuevas realidades cada vez más cambiantes, esto se enfoca principalmente en la variabilidad que existe tanto en los gustos de los consumidores como en la producción.

Según Piore y Sabel la crisis industrial se debe a la desfasada creencia que los consumidores son homogéneos, que genera que se continúe con una producción 
homogénea y masiva; contrario a eso, se introduce lo que se conoce como Producción Flexible, en donde la dirección productiva va enfocada de los consumidores hacia la producción, ya no de manera inversa, por lo que los bienes y servicios producidos se adaptan a los intereses de los clientes, que son cada vez más segmentados y con gustos cada vez más particulares y cambiantes (Piore \& Sabel, 1984). Esto lo muestra bien Lipovetsky al exponer casos como el de McDonald's, que ha tenido que comercializar el Big Mac sin queso en Israel, el que no tiene carne en la India, el Mac Spaghetti en Filipinas y el Mc Laks de salmón en Noruega. Además está el caso de Zara, que produce 12.000 nuevos diseños cada año (Lipovetsky, 2010).

Ante ello, la producción debe adaptarse a los cambios constantemente, y por eso es necesario desarrollar tecnología para sobrevivir, en donde el capital social sirve para que el conocimiento sobre la tecnología y los mercados fluyan rápidamente, aumentando la certidumbre para las decisiones (Botella, 2013). Sobre esto, Oswaldo de Rivero señaló que en el siglo XXI el poder mundial estará en la capacidad de poder innovar tecnológicamente para ganar competitividad y poder realizar negocios a escala mundial. En donde la carrera está en el sector donde el crecimiento de la demanda es la más rápida, justamente los productos con alto contenido tecnológico, que supera largamente a los demás tipos de bienes (manufacturas con baja tecnología y materias primas) (Rivero, 1998). Asimismo, para Lundvall, el aprendizaje y la obtención de los conocimientos necesarios en esta era de cambios rápidos solo puede darse con el capital social, señalando que es insostenible un crecimiento basado exclusivamente en capital intelectual y productivo (Lundvall, 2002).

Debido a esta situación, como lo indica Sodo y Hudson, las inversiones van a estar dirigidas principalmente al trabajo inmaterial (Sodo \& Hudson, 2006). Dentro de esta realidad se erige específicamente la innovación y desarrollo (I+D) en las empresas, que se trata en "desarrollar e implantar nuevas ideas para resolver problemas" (Dosi, 1988, pág. 1120), y en donde la innovación (y se debe agregar el desarrollo también) se convierte en "uno de los recursos más importantes de desarrollo de las economías, creando nuevas tecnologías y conocimientos. Permite mejorar los productos y procesos existentes, adoptarlas de otras dependencias económicas o crear nuevos bienes y servicios" (Mejía-Giraldo, Mendieta-Cardona, \& Bravo-Castillo, 2015, pág. 288).

\section{El capital social en la cooperación inter-institucional para el desarrollo de la} I+D

Pero el desarrollo en I+D no viene por las libres fuerzas del mercado, sino que requiere de esfuerzos coordinados (Ostrom \& Ahn, 2003), en donde el sector público trabaja para la cooperación entre los centros de educación superior, las industrias, los gobiernos y los laboratorios (Lederman, 1987). Estas redes forman el capital social, con un gobierno muy participativo para el desarrollo de este tipo de capital (Fountain, 1997).

González-Seijo, Muñoz y Pons estudian el desarrollo que se está dando en Cuba para ser una economía basada en el conocimiento a través del análisis de cuatro centros de investigación de la Universidad Central Marta Abreu de Las Villas (UCLV). Los autores señalan la necesidad que el Sistema Nacional de Ciencia e Innovación Tecnológica (SNCIT) del país ayude a conectar las distintas entes involucradas: financista-universidad-empresa-gobierno-sociedad para que trabajen cooperando unas con otras (González-Seijo, Muñoz , \& Pons, 2014).

Sobre esta relación, Noam Chomsky cuenta su experiencia cuando llegó al MIT en la década de 1950, donde esa institución fue uno de los lugares que el gobierno estadounidense financió para desarrollar tecnología (a través de la I+D) que después se beneficiarían las empresas privadas (Chomsky, 2016). 
Los pertenecientes a la OCDE gastan en promedio 2, 3 \% de su PBI en I+D, en donde los gobiernos cubren entre el 30 al 40 \% del gasto, con cifras astronómicas de Estados Unidos en la Guerra Fría (Chang H.-J. , 2015). Entre la década de 1950 y mediados de los noventa, la financiación del gobierno estadounidense representaba el 50-70 \% del total de dinero que se destinaba en I+D en el país, muy por encima del promedio del 20 \% de Japón y Corea del Sur. Esto fue vital para la industria tecnológica que hoy goza (Chang H. -J., 2008).

Los clusters -también conocidos como conglomerados o redes de empresas, las cuales funcionan cooperando unas con otras (Blacutt, 2013)- fomentan la innovación (Cainelli, Mancinelli , \& Mazzanti, 2007).

El capital social en clusters geográficos beneficia en la innovación, por ejemplo, en un estudio sobre clusters integrados por 50 empresas de calzados en la localidad de Valverde, que se encuentra al sur de España, se comprobó que a mayor capital social (basado en cuatro dimensiones: 1. cohesión, 2. diversidad, 3. relación y 4. recursos) existía mayor innovación, tanto para los productos como en los procesos productivos gracias al flujo de conocimiento (Casanueva, Castro , \& Galán, 2010). Lo mismo ocurrió en Silicon Valley, donde las empresas dedicadas a la tecnología computacional se integraron formando clusters para tener mayores probabilidades de éxito (Flores \& Yapuchura, 2016).

Un caso revelador que muestra la necesidad del capital social inter-empresarial es el del Apple y Microsoft. A finales de los noventa, Apple casi se va a la quiebra debido a que en vez de relacionarse con otras empresas quisieron hacerlo todo; a diferencia de Microsoft, que se especializó en desarrollar softwares mientras que se conectaba con otras empresas del rubro tecnológico para suministrase de los productos que requerían en vez de hacerlos ellos mismos; como por ejemplo, computadoras de Compaq o Dell, impresoras de Hewlett Packard, etc. (Cohen, 1998), con lo que pudo apoderarse del $90 \%$ del mercado de los sistemas operativos que se encuentran en los ordenadores personales (Giddens, 2001).

\section{Capital social intra-empresarial}

$\mathrm{Al}$ interior de las empresas también se requiere que los trabajadores tengan nuevos conocimientos y habilidades, que se originan justamente por el capital social, en las interacciones que hay dentro de las relaciones sociales (Lesser \& Cothrel, 2001), para ello, se requieren relaciones horizontales, no verticales. En la etapa fordista, se contaban con muy pocos trabajadores especializados y muchos no especializados, entonces se creaba una relación vertical donde estos últimos realizaban trabajos pequeños y repetitivos supervisados por los primeros, pero ahora la realidad ya cambió, en la actualidad hay muchos trabajadores especializados, por lo que las vinculaciones deben ser más homogéneas (Cohen, 1998), y por ende, las relaciones deben ser horizontales.

Además, debido a quela dirección para producir se ha invertido (ahora va del consumidor a la cadena de producción), se requiere un flujo de conocimiento e información rápido. Lo que significa que el bien y/o servicio ha sido vendido antes de haberse producido. Por esta razón es que las relaciones entre los trabajadores deben ser horizontales para evitar la lentitud de las relaciones verticales (Sodo \& Hudson, 2006).

Ante esto, por ejemplo, en Silicon Valley se tiene como norma en las corporaciones e industrias que las relaciones sean horizontales, acortando la cadena de mando. Simplemente, las empresas burocráticas y con relaciones verticales ya no pueden sobrevivir ante la competencia del mercado (Ostrom \& Ahn, 2003).

Se puede ver que desde las aperturas de las economías, principalmente dadas desde los setenta, es que las empresas deben apelar a cambios constantes de sus 
producciones para poder adaptarlos a consumidores cada vez más cambiantes también; ante ello, es que es vital la investigación y el desarrollo. El capital social para este fin puede ser inter-institucional por medio de la coordinación entre diversas entidades, principalmente sector público - universidades - industrias - laboratorios como lo hicieron los países de la OCDE, e intra-empresarial basadas en relaciones horizontales de los trabajadores principalmente para poseer un flujo de información más fluida.

\section{Capital social en la autogestión económica}

La autogestión es cuando los propios trabajadores administran de manera democrática la empresa, pero si lo entendemos en un sentido más amplio se refiere a la organización por parte de la propia sociedad para una participación ciudadana con una distribución equitativa del poder en las tomas de decisiones, y donde también se protegen los derechos de las minorías (Knight \& Roca, 9 al 27 de junio de 1975).

Es decir, la autogestión se refiere a la actitud y comportamiento interactivo que tienen las personas entre ellos en la vida, no se limita, como en las cooperativas, a los medios de producción. Se caracteriza principalmente por la autonomía y la participación activa (Miranda, 2011).

Uno de los primeros ejemplos de la autogestión es la Comuna de París, que se instaura el 28 de marzo de 1871 por un pueblo en armas que luchaba en contra de las reparaciones a Prusia por la guerra y que se caracterizó por defender la autonomía local y estar en contra del centralismo. Por lo cual, se implantó un sistema de gobernanza descentralizado, caracterizado por municipios libres, en donde existía una democracia participativa por sus habitantes; un predominio en la colectividad; autonomía comunal y asociación voluntaria.

En el plano económico, se estableció un sueldo máximo a los funcionarios de la Comuna que no podía superar al del obrero (6.000 francos), se convirtieron los centros de producción abandonados en cooperativas con el objetivo de mejorar las situación de los trabajadores a través de mejores salarios y el empleo. Las cooperativas se organizaron en una Unión de Cooperativas (Lida \& Illades, 2001) (Ruiz, 2001).

La gestión de esas empresas eran democráticas, donde los propios trabajadores decidían las personas que debían ocupar los puestos de jefes, tenían el poder de despedirlos, establecían los salarios, los horarios, las condiciones laborales y se planificaba lo que se iba a hacer al día siguiente a través de un comité (Novaes, 2011).

Otro caso se da en la Guerra Civil Española (1936 - 1939), en donde predominó la autogestión, por ejemplo, en el plano económico los medios de producción fueron gestionados por los trabajadores haciendo que sean ellos mismos los dueños de los medios en donde trabajaban (colectivización) -tanto de la tierra, como de las empresas-. Buendía hace una descripción sobre cómo fue la economía durante ese periodo, tanto en el campo como en la ciudad.

En el campo, los sitios donde se decidía la colectivización se agrupaban en grupos pequeños de cinco a diez personas con un delegado y con estatutos que variaban según el lugar. Las decisiones se tomaban a través de las asambleas y se elegía un comité administrativo (Buendía, 2002).

En cuanto a la producción, cada agricultor tenía una parcela privada y otra colectivizada. En algunos lugares los salarios se determinaban por necesidad de las personas y no por rendimiento. Para el intercambio entre colectividades se crearon cooperativas de compra y venta que se encargaban de las transacciones y hubo cajas de compensación para que las colectividades ayudasen a sus homólogos (Buendía, 2002). 
En la ciudad, los trabajadores se hicieron cargo de los medios de producción ante la huida de los dueños. Al igual que en el campo, las decisiones se tomaban a través de asambleas y también había un comité administrativo (Buendía, 2002).

Por ejemplo, Méndez y Vallota estudian la autogestión de las empresas en Barcelona. Señalan que estaban organizadas en sindicatos, que al mismo tiempo se subdividían en grupos que eran autónomos, cada grupo tomaban sus propias decisiones en asambleas donde participaban todos, además contaban con un delegado que los representaba cuando se debían tomar decisiones a nivel de fábrica o región (Méndez \& Vallota, 2001).

En el plano productivo, se manifestó la creatividad de los trabajadores gracias a la libertad en las tomas de decisiones, por ejemplo, hubo cambios de rubros productivos dirigiéndolos a los sectores que tenían gran demanda, como producir productos para la guerra; además, se implantaron mejoras e innovaciones productivas, como por ejemplo, la creación de nuevos modelos en las líneas de producción (Buendía, 2002).

Hubieron empresas que demostraron su eficiencia, por ejemplo, la Compañía de Autobuses de Barcelona dobló sus servicios, aportó a actividades recreativas en la ciudad y produjo armas. Todo esto con una disminución del personal producto de la movilización al frente de batalla (Méndez \& Vallota, 2001).

No se puede hablar de la autogestión en la Guerra Civil sin mencionar a los anarquistas, que tuvieron un rol importante en la administración autogestionaria, ellos apelaron a la solidaridad y ayuda mutua para salir adelante (González, 2011). De hecho, hubieron cuatro organizaciones ligadas al anarco-sindicalismo que fueron muy activas durante ese periodo, la Confederación Nacional del trabajo (CNT), la Federación Anarquista Ibérica (FAI), las Juventudes Libertarias y Mujeres Libres (Bernecker, 1982).

González cuenta un hecho donde se muestra la solidaridad y la ayuda mutua de estas agrupaciones, que fue cuando las personas de la región de Cehegín, en Murcia pidieron abono para poder cultivar en los terrenos pero no contaban con nada para obtenerlos, pero igual así se decidió hacer todo lo posible para poder ayudarlos (González, 2011).

Cabe señalar que a nivel social, tanto en el campo como en la ciudad, se implantó la seguridad social (como por ejemplo, pensiones a ancianos), prestaciones sanitarias, trabajos de alfabetización, se crearon colegios con obligatoriedad a la asistencia para que los niños no trabajen, institutos de capacitación, bibliotecas, teatros, cines, etc. (Buendía, 2002).

Yendo al plano Latinoamericano, está el caso peruano de Villa El Salvador, en la ciudad de Lima, que se originó como una invasión de 50000 personas en 1971 a lo que era simplemente un arenal. Inmediatamente en su proceso de desarrollo crearon centros recreativos para actividades en común, designaron delegados que los representaran, formaron unidades de organización para abarcar los temas públicos e iniciaron un proyecto de construcción en base a la acción voluntaria que produjo casas, centros educativos, bibliotecas, pistas, etc., con lo cual pudieron mejorar enormemente sus vidas. Lo que también repercutió en el plano económico, como la creación de cooperativas de mercados, asociaciones de empresas y comerciantes, comedores populares, etc. (Kliksberg, 1999).

En Argentina se puede encontrar la autogestión con la recuperación de empresas por parte de sus trabajadores convirtiéndolas en empresas autogestionadas a partir de los noventa con el objetivo de no perder sus puestos de trabajo, pero fue por la crisis del 2001 que se hizo masivo, en total, hay un aproximado de 350 empresas recuperadas (cálculo hecho en 2013) con alrededor de 25.000 trabajadores en total (Rodríguez N. , 2019). 
Sodo y Hudson señalan que en estas empresas autogestionadas se eliminó las relaciones verticales basadas en las jerarquías, se crearon grupos autónomos para el trabajo y existe una multifuncionalidad que debe hacer cada trabajador. Hay mayor comunicación entre trabajadores, lejos del trabajo en silencia que primaba antes, por lo que hay reuniones constantes, conversan y se consultan, promoviendo la cooperación; además existe un mayor despliegue de capacidades humanas en el trabajo (Sodo \& Hudson, 2006).

Por ejemplo, en su estudio basado en una de las empresas autogestionadas en Rosario descubren que hay una alta interacción entre los trabajadores y existe una aplicación alta del intelecto por parte de ellos; puesto que deben crear, innovar, idear, resolver problemas, etc.; muy lejos del trabajo repetitivo y autónomo que debían cumplir antes (Sodo \& Hudson, 2006).

Una expresión de ello es que para solucionar el problema de falta de capital para la producción, algunas de estas empresas introdujeron la modalidad del trabajo façon, que consiste en que se consigue a un inversionista para que provea de materia prima e insumos y, a cambio, compra la producción a un precio establecido, por lo que la empresa baja su rentabilidad por unidad producido pero obtiene recursos para poder producir y obtener ganancias; esta alternativa termina siendo una mucho mejor opción que simplemente cerrar (Ruggeri, 2011).

Wyczykier estudió cuatro empresas recuperadas (la Cooperativa de Trabajo (CT) Adabor, la CT L.B, la CT Artes Gráficas El Sol y FASINPAT) y encuentra que las acciones tomadas fueron para mantener sus trabajos anteriores (no por emancipación), se crearon nuevas relaciones interpersonales basadas en la solidaridad y en la afectividad; y además, se crearon formas de autoridad y regulación colectiva distinta a la relación jerárquica tradicional (Wyczykier, 2009).

También existe solidaridad entre los trabajadores de las empresas autogestionadas con el exterior, que se manifiestan a través de la cesión de lugares para actividades de la comunidad, colaboración con otras empresas recuperadas y a otras organizaciones, etc. (Diaz, 2015).

Los casos mencionados son ejemplos que la población se puede autoorganizar, siempre y cuando posean un alto capital social, para poder llevar adelante proyectos en conjunto, pero a veces se requiere ayuda para lograr esa autoorganización Por ejemplo, Putnam y Feldestein muestran asociaciones civiles autoorganizadas que han podido involucrarse en el mejoramiento y satisfacción de asuntos públicos, pero sí aceptan que debe existir entidades que fomenten la participación ciudadana (Putnam \& Feldstein, 2003). Ante esto, el sector público puede ser un aporte importante para fomentar la cooperación y participación (Pisani, Franceschetti, Secco, \& Christoforou, 2017).

Un caso al respecto es en el distrito de El Agustino, en la ciudad de Lima - Perú, donde en los ochenta el gobierno municipal de turno creó los MIADES (Micro áreas de desarrollo), que consistía en aglomerar las organizaciones civiles existentes para que puedan resolver los problemas públicos de manera autogestionada y autoorganizada, principalmente para obtener bienes tanto del sector público como privado y para que participen en la gestión y planificación urbana (Tanaka, 1999).

En las comunidades campesinas de Chiquimula (Guatemala), se ejecutó en los noventa el Programa de Apoyo a los Pequeños Productores de Zacapa y Chiquimula (PROZACHI) por siete años, también apoyados por el Fondo de Inversión Social (FIS) a través de la construcción de infraestructura, que con capacitaciones para fomentar el capital social pudieron convertir el predominante comportamiento individualista y de dependencia de los campesinos a uno basado en la confianza y la cooperación, que sembró la semilla para que mejoraran sus ingresos económicos (Durston, 1999). 
En Buenos Aires se ejecuta el Programa de Autogestión de la Vivienda, que surge a partir de la sanción a la Ley 341 en el 2000, y consiste en otorgar créditos colectivos con tasas de interés subsidiados y con plazos de hasta 30 años para viviendas a personas con bajos recursos (Rodríguez \& Zapata, 2020).

Rodríguez y Zapata hacen un estudio en el 2018 tanto de los beneficiarios de la Ley 341 como del Programa. Abarcan a 120 cooperativas (60\% de familias del total de beneficiarios) y descubren que la ejecución de manera autogestionada generó construcciones en buenas locaciones, altas superficies en las viviendas, buenos materiales, buenos acabados y la creación de espacios comunes, demostrando que el sistema produce una eficiencia en la administración de los recursos del Estado. Además, también señalan que el hecho de pertenecer a redes y organizaciones (capital social) se convirtió en un activo para acceder a una vivienda, combatir la pobreza y la precariedad (Rodríguez \& Zapata, 2020).

Es imposible hablar de autogestión sin mencionar al socialismo autogestionario de la ex República Federativa Socialista de Yugoslavia (1945-1992), que adoptó este sistema después de la ruptura definitiva con la URSS en 1949 y donde la autoorganización abarcó tanto el ámbito económico, político y social.

El sistema fue orquestado por el propio Estado, con el mariscal Josip Tito a la cabeza, en donde se transfirió poderes a los municipios y demás instituciones, incluyendo los medios de producción. Con lo cual se configuró una gestión basada en el Estado, trabajadores y usuarios (Rodríguez \& Ciolli, 2011).

En junio de 1950 por medio de la “Ley Básica sobre la Gestión de Empresas Económicas Estatales y Altas Asociaciones Económicas" las empresas pasaban de ser estatales a ser sociales, convirtiendo a los trabajadores como los dueños de los mismos. Además, entre 1949 y 1953 se reorganizó la representación política para que en las comunidades locales el poder sea descentralizada y basada en la autogestión (Cosovschi, 2018).

Romero y Lluis Navas muestran la organización dentro de las empresas, a través de los órganos para la autogestión:

a. Colectivos obreros (también llamados asambleas de personal o colectividad obrera) estaba integrada por todos los trabajadores y tenían el poder de generar las políticas más importantes, crear comisiones según los temas que se consideraban como necesarios (reclamaciones, salud, productividad, etc.) y elegir los integrantes del consejo obrero.

b. Consejo obrero, el número de integrantes dependía del tamaño de la empresa, pero usualmente oscilaba entre 15 y 120 miembros. Contaban con comisiones en temas especializadas, una de esas comisiones estaba integraba por representantes del personal, sindicatos y autoridades locales que se encargaban de juzgar en concurso público a los puestos directivos y de dirección.

En este consejo no podía pertenecer el director, y se renovaba los miembros cada dos años (la mitad cada año). Funcionaba como asamblea legislativa y se encargaba de decidir sobre el comité de gestión y sobre el director, ya sea para elegirlos o revocarlos; además, adoptaban reglamentos internos, ejecutaban planes financieros, productivos, de inversiones y de amortizaciones; sumado a esto, aceptaban el balance y las cuentas relacionadas a la empresa, e incluso, dirigían la política de los trabajadores.

c. Comité de gestión, estaba integrado por tres a once personas, donde se encontraba el director como uno de los miembros. Funcionaba como una junta rectora, se encargaba de informar al consejo de obreros sobre el funcionamiento de la empresa, además de tener la posibilidad de presentar proyectos, controlar lo 
que hace el director y sus colaboradores; y sumado a esto, realizaba todos los preparativos para que los trabajadores tomen decisiones.

d. Director, se encargaba de vigilar e inspeccionar todo lo relacionado al funcionamiento técnico y administrativo, además de ser un representante ante entidades fuera de la empresa, como por ejemplo, ante el Estado. No podía decidir sobre el despido o contratación del personal ni tomar decisiones importantes sin que tenga la aceptación del consejo de obrero (Romero, 1994) (Navas, 1977).

En cada fábrica había una sección sindical con su comité, que se encargaba de dar servicios a los obreros, hacer de conciliador, controlar los órganos involucrados en la autogestión, promover la productividad laboral y realizar acciones en contra de las ausencias injustificadas en el trabajo. También hacían las listas de candidatos para el consejo obrero, elaboraban los convenios colectivos para los salarios y podían convocar reuniones para tomar decisiones (Navas, 1977).

En 1974 se creó las "organizaciones básicas de trabajo asociado" conocidas como "OOURS" ("Osnovnih Organizacija Udruzenog Rada"), en donde se hizo que las áreas elementales de gestión y producción conformados por unos 40 a 80 trabajadores de una misma unidad técnica se asociaran para trabajar conjuntamente y se evaluaran entre ellos mismos. El conjunto de estas da como resultado a la empresa (Romero, 1994) (Bastos, 1978).

Gracias a esta organización los trabajadores pudieron ejercer de manera directa sus derechos de autogestión. Con lo cual se descentralizó el poder y posibilitó que todos pueden tomar decisiones sin importar el puesto de trabajo que ocupaban (Romero, 1994) (Bastos, 1978).

La autogestión trascendió lo económico pasando a los sectores políticos y sociales. En lo que respecta a lo político, el órgano principal de gobierno de la comuna era del comité popular, que era bicameral y se componía del consejo comunal (elegido por sufragio de todos los ciudadanos) y el consejo de productores (elegidos por productores agrícolas, industriales y del sector servicio) que tenían entre 15 a 20 miembros según la comuna y se renovaban cada 4 años (Romero, 1994).

Para su labor se ayudaban por comisiones especializadas, también había un presidente, que era del comité popular y se encargaba de hacer coordinaciones y supervisiones de la administración y rendía cuentas al secretario del comité (Romero, 1994). Además, se encontraba el Consejo Sindical Comunal y que tenía como función la de coordinación y el de generalizar los reglamentos (Navas, 1977).

A nivel social también se expandió el sistema autogestionario a nivel de colegios y las múltiples instituciones existentes (hospitales, culturales, etc.). Por ejemplo, en las escuelas, además del director que trabajaba como administrador, también estaban el consejo docente (formado por maestros y que decidían sobre los aspectos de la enseñanza) y el comité escolar (que era nombrado por el Comité Popular de la Municipalidad y representaba a los estudiantes para que recibieran becas, decidían sobre temas de disciplina, etc.) (Navas, 1977).

Lluis y Navas, quien estudió la República mientras seguía unificada, consideró la economía Yugoslava como un éxito, con índices de desarrollo de los más altos del mundo. Destacando que en 1960 la renta per cápita era el triple a comparación del periodo anterior a la guerra (Navas, 1977).

Yugoslavia tuvo un alto crecimiento en las décadas del cincuenta y sesenta (entre 1953 a 1963 las tasas de crecimiento económico fueron en promedio de 9, 5 \% anual), además de la alta urbanización, un crecimiento importante en el consumo personal 
y a la multiplicación en la cantidad de industrias, demostrando así la efectividad del sistema autogestionario (Cosovschi, 2018).

Entre 1954 a 1960 las manufacturas que se exportaban se duplicaron y tuvieron millones de turistas (alcanzando los 5 millones) que posibilitó el desarrollo de hoteles y carreteras. Entre 1955 a 1972 Yugoslavia pudo octuplicar su producción de electricidad, además de triplicar en zinc y acero; y también, aumentó su producción de automóviles turísticos (de 800 a 110.000) En lo que respecta a tecnología, se realizaron contratos de colaboración entre empresas nacionales con internacionales para el uso de patentes, maquinarias, etc. Por ejemplo, la empresa Zastava tuvo un acuerdo con Fiat y pudo fabricar autos (Navas, 1977).

En general, a pesar de las dificultades que se encontraron en el camino, este sistema permitió que Yugoslavia pudiera superar sus problemas culturales, sociales y económicos en un plazo relativamente corto (Romero, 1994).

La caída de Yugoslavia se debió a la fragmentación interna que había comenzado en la década de los setenta y que se agudizó a partir de la muerte de Josip Tito, con lo que las repúblicas comenzaron las guerras para independizarse. Además estuvo la crisis del petróleo (en 1973 la OPEP aumentó el precio de esta materia prima creando una crisis mundial), las políticas liberales que habían generado fuertes deudas externas -cabe recordar que en ese periodo la Reserva Federal estadounidense alzó los tipos de interés, aumentando de manera enorme y rápida (Klein, 2010)- y la alta intervención de organismos internacionales en la economía de la república (Cosovschi, 2018).

Es así que en el modelo autogestionario se puede observar dos tipos, el que se origina por iniciativa de la población -la Comuna de París, la Guerra Civil Española, Villa El Salvador en Perú y las empresas recuperadas en Argentina- y los que son fomentadas por el Estado -los MIADES en El Agustino en Perú, el programa de apoyo en Chiquimula en Guatemala, el programa de autogestión de viviendas en Buenos Aires y en el socialismo autogestionario de Yugoslavia de Josip Tito-, en ambos se encuentra que debido a que la autogestión posee un sistema descentralizado y depende netamente de los integrantes, la existencia del capital social es fundamental en sus miembros.

\section{Capital social laboral}

En el estudio de Charles-Leija, Torres y Castro sobre el aporte del capital social en conseguir empleo en México encuentran que sí existen una relación entre ambos. El tener más de tres amigos aumenta las probabilidades de conseguir trabajo gracias a la información que obtienen de ellos sobre ofertas y salarios (Charles-Leija, Torres, \& Castro, 2018). Además, Sanders y Nee encuentran que debido a las características de alto capital social de las familias en los inmigrantes asiáticos e hispanos asentados en Estados Unidos se correlacionan con mayores probabilidades de tener empleo y mejores ingresos (Sanders \& Nee, 1996).

Una vez que se consigue el empleo, el capital social puede servir para mejorar sus condiciones laborales, debido a que los trabajadores se pueden apoyar mutuamente. Ya Marx señaló que los trabajadores, debido a la situación que en la que se encuentran, se identifican unos con otros, con lo cual se pueden apoyarse mutuamente (Portes, 1998). Esto lo muestra Kröpotkin cuando menciona a las uniones obreras, que tenían como fin ayudarse entre ellos para sobrevivir a las condiciones que se encontraban (Kröpotkin, 2005). Posteriormente, se puede seguir con las revueltas en Estados Unidos y demás países para lograr mejores condiciones laborales como el derecho a las ocho horas de trabajo, entre otros.

Esta situación de apoyo entre trabajadores se puede dar incluso ante la represión del gobierno de turno, por ejemplo, en la dictadura franquista los sindicatos en contra 
del gobierno igual se organizaron en la clandestinidad y continuaron denunciando injusticias laborales, además de apoyar causas en común, como lo muestra BermúdezFigueroa, Serrano y Roca en la ciudad de Cádiz (Bermúdez-Figueroa, Serrano, \& Roca, 2019). Lo que demuestra un capital social muy fuerte gracias a su identificación como trabajadores.

En el caso de las empresas recuperadas de Argentina, distintas agrupaciones como los sindicatos, por ejemplo, la Federación Gráfica Bonaerense, la seccional UOM Quilmes y Matanza, el sindicato ceramista de Neuquén - SOECEN-, el MNER y el MNFRT fueron claves para la recuperación de empresas y la lucha de los intereses de los trabajadores posterior a la instauración de la autogestión (Wyczykier, 2009).

En cuanto a los procesos de recuperación se trasladaron recursos (como alimentos por ejemplo), se proveyeron de asesorías legales, se apoyó en los enfrentamientos, ayudaron en los gastos a través de dinero, etc., mientras que en la etapa posterior a la recuperación, se movilizaron para la obtención definitiva de los trabajadores sobre las empresas, generaron encuentros entre trabajadores de empresas recuperadas, ayudaron a difundir masivamente información sobre la situación de estas empresas, etc. Con lo que se muestra la identidad formada por lazos debido a la pertenencia grupal de un nosotros (trabajadores) con los demás (Wyczykier, 2009).

Otra ventaja del capital social a nivel laboral es para defender los salarios, por ejemplo, en la crisis del setenta, en los países de la OCDE se vivió una situación atípica a nivel laboral. Mientras que el desempleo aumentaba, los salarios subían, esto no tiene lógica, puesto que el aumento de la oferta laboral debería hacer descender los salarios. La explicación es la teoría insiders/outsiders, que consiste en la protección de los salarios gracias a las negociaciones entre los empleados con los empleadores, en donde este se determina según su productividad y no por el potencial productivo de los desempleados (Cohen, 1998).

Schuldt ha comprobado a través de su estudio que realizó sobre el periodo de los noventa en el Perú (etapa clave puesto que es cuando se aplica el ajuste estructural que comienza a disminuir los sindicatos, sobre todo entre 1995-1996) que la sindicalización y la negociación colectiva protegen los puestos de trabajo y los salarios, por lo que producen mejores resultados en ambos aspectos a comparación de los trabajadores no sindicalizados (Schuldt, 2004).

Cabe indicar que varios países industrializados de Europa (como Alemania, Suecia, Noruega, etc.) reconocen la importancia de los sindicatos; sobre todo, por el beneficio que trae las negociaciones colectivas. Por ejemplo, cuando Volvo compró una rama de Samsung les pidió que crearan un sindicato porque no sabían cómo gestionar la empresa sin tener una negociación colectiva para determinar las condiciones de trabajo; lo mismo ocurre en Volkswagen, donde los trabajadores también son involucrados en las decisiones de la empresa (Chang H.-J. , 2015). Lo mismo ocurre en tiempos de crisis, por ejemplo, Stiglitz resalta que una de las características que tenían los países que pudieron responder eficazmente a la crisis financiera del 2008, como Alemania o Suecia, tenían sindicatos fuertes (Stiglitz J. , 2015).

A nivel macro, por ejemplo en Suecia en 1938, la central obrera (LO) y la agremiación de empleadores firmaron el Tratado de Saltsjöbaden, que fueron la base para la constitución del estado de bienestar que hoy goza el país. Principalmente abarcó los temas de la negociación colectiva, los salarios y los tributos por parte de los empresarios, que serían dirigidos hacia el bienestar social de la nación (Béjar, 2011) (Chang H. -J., 2008).

En Holanda, se estableció un acuerdo en Wassenaar en la década de los ochenta, en donde los sindicatos aceptaron a una reducción de las horas de trabajo a cambio de una disminución del salario. Esto trajo como consecuencia menores costes a nivel 
laboral, mientras que la economía ha seguido creciendo y con un nivel de desempleo bastante bajo (Giddens, 1999).

Con los casos descritos -las relaciones amicales en México, las familiares de inmigrantes en Estados Unidos, las laborales en Cádiz, Argentina, países de la OCDE, Perú y Europa- se puede observar que el capital social aporta para conseguir empleo y mejorar las condiciones de vida de estas personas.

\section{Capital social financiero}

El sistema financiero se trata del total de involucrados en la acción de traspasar ahorros para que sean usados de manera productiva (Banco Mundial, 1989), su relación con el capital social consiste en la confianza que debe existir debido al problema de la asimetría de información entre los agentes (Pérez \& Fernández, 2006).

En lo que respecta a las microfinanzas, es relevante porque abarcan los sectores excluidos por la banca tradicional y tienen un rol importante en aliviar la pobreza. Además, el microcrédito posibilita emprendimientos quehacencrecer económicamente a una región (Espinoza, Salas , \& Samaniego, 2019).

En Cataluña, durante la Guerra Civil, las empresas colectivizadas tenían serios problemas de financiación, para solucionarlo crearon en 1937 la Caja de Crédito Industrial y Comercial (CCIC) que se financiaba por el gobierno y la mitad de los beneficios de las empresas colectivizadas (Buendía, 2002).

En Estados Unidos, ciertos grupos de inmigrantes asiáticos se agrupan en reuniones que tiene como fin aportar un monto para crear un fondo común que es entregado por turnos a cada persona, se trata de un crédito rotativo (Light, 1984) (Light \& Bonacich, 1988).

En el Perú también ocurre eso con los inmigrantes japoneses, con el nombre de Tanomoshi. Sus orígenes abarcaban problemas a corto plazo (dinero, desnutrición, trabajo, etc.) y a largo plazo (aprendizaje de técnicas productivas, oficios, etc.), en donde uno de los rubros de esa ayuda consistía en el financiero, para lo cual se reunía un fondo común que pasaba de manera alternada con el fin de ayudarse unos a otros, esta práctica se sistematizó y se convirtió en un institución donde se sigue practicando hasta la actualidad, aunque de manera distinta a sus orígenes (Tokeshi, 2009).

En el estudio de Espinoza, Salas y Samaniego que abarcó a 3989 microempresarios de la provincia de Loja (Ecuador) encontraron que el 66 \% de ellos señaló que gracias al microcrédito su responsabilidad con su emprendimiento mejoró por la responsabilidad de tener que pagar la deuda; el 58 \% manifestó que sus ventas aumentaron; el $54 \%$ dijo haber invertido correctamente el préstamo, lo que les permitió acceder a nuevas oportunidades de negocio; además, el 61\% indicó que gracias al microcrédito mejoró sus relaciones con su entorno personal (Espinoza, Salas , \& Samaniego, 2019).

A través del estudio en áreas urbanas de cuatro comunidades pobres de distintos países (Zambia, Ecuador, Filipinas y Hungría), Moser encontró que las familias pobres se ayudan mutuamente para sobrevivir económicamente de los duros momentos, uno de los mecanismos usados es el crédito informal (Moser, 1998).

En cuanto a las cooperativas, estas tienen un problema serio de financiación, por lo que han tenido que recurrir a distintos mecanismos para resolverlo. El más utilizados, y que ha sido de los más extendidos en los países de la Unión Europea, es la financiación gracias a los aportes de inversores externos, alejándose de su modelo tradicional pero apelando al capital social, específicamente con fuentes externas (Carrau, 2017). Esto muestra que debe existir capital social tanto a nivel interno de la organización (algo propio de las cooperativas) pero también a nivel externo, es decir, fuera del mismo. 
Para solucionar este problema la cooperativa más grande del mundo - Mondragón - creó en 1959 la Caja Laboral Popular, que desde sus inicios cumplió tres objetivos: captar capital para invertir, atender necesidades sociales y la integración cooperativa. Se trata de un sistema donde las cooperativas están asociadas y tienen tanto beneficios (recursos financieros) como obligaciones (importe a la Caja). Además, también cuentan con el Fondo Intercooperativo de Solidaridad (FISO) que ayuda a las cooperativa que están en crisis (Altuna, Loyola, \& Pagalday, 2011).

En Cuba, cuando los centros financieros se van del país posterior al triunfo de la revolución, se genera un serio problema de financiación, por lo que los agricultores que se beneficiaron de la reforma agraria deciden unirse y crean las Cooperativas de Créditos y Servicios (CCS), en donde los integrantes obtienen créditos, tecnologías y otros servicios beneficiosos para la producción; y ha traído como resultado que, de los cinco modos existentes de sociedades productivas en el sector agropecuario cubano, una de las que tienen mayor eficiencia son justamente las CCS (Nova, 2011).

Grameen Bank es un banco fundado en 1983 por el economista Muhammad Yunus que trabaja contrario a las prácticas de las bancas comerciales, en esta prima la solidaridad y la confianza ofreciendo préstamos y financiamientos productivos a los pobres de Bangladesh. En 2019 ya contaba con más de 9 millones de miembros de 81 . 678 pueblos, con lo cual cubre al 93 \% de pueblos del país (Kliksberg, 1999) (Bottasso, 2004) (Grameen Bank, 2019).

En Bangladesh, el economista Jeffrey Sachs indica que en el 2003 conoció una asociación de mujeres dedicadas al comercio que la ONG BRAC (Bangladeshi Rural Advancement Committee) habían colaborado en organizarlas. Las emprendedoras estaban agrupadas por equipos de seis personas que recibían créditos colectivos, en donde todas eran responsables de cada una de sus miembros para el pago de las mismas. Esta modalidad de crédito colectivo fue introducido por primeras vez tanto por el BRAC como por Grameen Bank obteniendo muy buenos resultados (Sachs, 2006).

En Brasil hay una extendida práctica de las finanzas basadas en la solidaridad, como por ejemplo, las cooperativas de créditos, bancos comunitarios, cooperativas sociales y cooperativas de recicladores (Singer \& Schiochet, 2016).

En el Perú, durante la hiperinflación del primer gobierno de Alan García, los hermanos puneños Guisado, quienes son propietarios de varias galerías de Gamarra apoyaron a su comunidad para que pudieran tener un préstamo bancario y así enfrentar la crisis que se vivía. Esta cooperación financiera también se da entre familiares dueñas de las empresas en Gamarra, puesto que muchos no utilizan la banca comercial sino que dependen principalmente de sus lazos parentales para obtener préstamos (Cornejo, 2005).

Esto mismo ocurre con los empresarios Icheños en Caquetá, que también apelan a formas de créditos informales entre ellos para ayudarse en sus respectivos negocios (Huber \& Lamas, 2017).

Con las experiencias descritas en Cataluña durante la Guerra Civil Española, en los inmigrantes asiáticos en Estados Unidos y Perú, en Loja (Ecuador), en las comunidades estudiadas por Moser, en las cooperativas en la Unión Europea, en Mondragón, en Cuba, Bangladesh, Brasil y Perú se puede observar que el sistema de crédito es importante, y un factor clave es la confianza (capital social) entre los agentes para que sea exitoso.

\section{Voluntariado}

Martínez-Cárdenas, Ayala-Gaytán y Aguayo-Téllez descubren que existe un multiplicador de la confianza (que es un elemento esencial en la cohesión de las 
personas en el capital social), que consiste en la percepción que se tiene de alguien ayudando a otras personas, esto aumentará la confianza y generará una mayor propensión de que las personas se ayuden mutuamente (Martínez-Cárdenas, AyalaGaytán , \& Aguayo-Téllez, 2015). Lo que significa que el voluntariado es un punto clave para producir ese efecto.

Esto lo saben muy bien en el municipio de Marinaleda (en Andalucía - España) con sus Domingos Rojos. En este municipio, durante la transición democrática que vivió España es que gobierna el Sindicato de Obreros de Campo (SOC) a través del CUT (Candidatura Unitaria de Trabajadores), que es la fuerza política que prevalece hasta la actualidad desde que ganó su primera elección en 1979, con un manejo político basado en lo que han denominado como Poder Popular, teniendo como su principal ideología política de que la tierra es para quien lo trabaja.

En este lugar, los domingos se realizan trabajos voluntarios, conocidos como Domingos Rojos, y tiene principalmente dos fines; el primero, para mejorar aspectos del pueblo a través de estas acciones públicas (como por ejemplo, el recojo de la basura); y el segundo, aumentar la cohesión del colectivo a través del fortalecimiento de la identidad y la solidaridad, se trata de romper con la competencia que fomenta el odio entre las personas (Talego, 1995).

A nivel macro, los pobladores de los países nórdicos tienen una alta confianza interpersonal (Portela \& Neira, 2002) y donde existe una gran cantidad de organizaciones voluntarias (Mavares, Díaz, Colina, Lombardi , \& Prieto, 1999), por ejemplo, en Suecia el Estado fomenta la participación social a través de la creación de múltiples asociaciones juveniles (Sánchez, 2013). Recordando que el capital social -basado en la alta confianza interpersonal y en la pertenencia a algún grupo voluntario- tiene una relación con el crecimiento económico (Portela \& Neira, 2002), se puede inferir que es uno de los factores, sin soslayar que hay otras variables, para que los nórdicos tengan rentas per cápita muy altas, que siempre aparezcan entre los primeros puestos en rankings económicos como en el Ranking de Competitividad Mundial, además que posean bajos niveles de corrupción y baja desigualdad económica (Frediani, 2011). Justamente Kuznets considera una ventaja comparativa de los pequeños países la fuerte interacción que existe en sus poblaciones, lo que genera fuertes relaciones entre ellos y sus organizaciones (Kuznets, 1960).

Además de que los voluntariados beneficien al capital social que posibilita un crecimiento económico, estas acciones per se repercuten en la economía directamente, por ejemplo, en Israel, donde un cuarto de la población realiza trabajos voluntarios, y esas labores representan un valor de 8 \% del PBI (Mavares, Díaz, Colina, Lombardi , \& Prieto, 1999).

Como se puede ver con los casos de Marinaleda (Andalucía - España) y en los países nórdicos, el voluntariado ayuda a formar el capital social, principalmente por generar confianza entre los pobladores. Sumado a ello, esto tiene una repercusión positiva en la economía.

\section{Conclusiones y Discusiones}

La interacción es el primer requisito para que exista capital social, ya que esta última se basa en la relaciones interpersonales, en donde gracias a este tipo de capital es que se pueden conseguir beneficios. Por ejemplo, está el caso de los trabajadores, estos pueden interactuar y crear lazos entre ellos mismos debido a los objetivos en común que persiguen y que los impulse a actuar de manera conjunta para poder lograr objetivos en común (Bacile \& Ferreyra, 2012), pero esto también se extiende a nivel étnico, familiar, ciudadano y cualquier otra característica identitaria en común 
que puedan compartir las personas y que gracias a ello puede ser aprovechado para la formación del capital social.

El capital social posibilita mecanismos de articulación social facilitando el acceso a bienes y servicios (Sánchez, 2013), como en el caso de la Investigación y Desarrollo (I+D), insumos, conocimientos, etc., con lo cual aumenta la posibilidad de ser usado para mejorar económicamente, tanto a nivel individual como colectivo.

El capital social reduce los costes relacionados a las transacciones (Rodríguez, 2012), debido a que se evitan contratos, abogados, entes que supervisen el cumplimiento, juicios, etc. Por ejemplo, los comerciantes judíos de diamantes en New York evitan costos en sus transacciones gracias a los lazos existentes entre ellos y los fuertes castigos para los que rompen eso (Portes, 1998).

Para un mejor trabajo dentro de las empresas se debe dividir en núcleos pequeños, esto porque los grupos de pocos miembros trabajan mejor, son más coordinados y eficaces (Méndez \& Vallota, 2001), además deben tener una relación horizontal con alto capital social. Esta forma de administración supera a las relaciones verticales, burocráticas y de gran tamaño que trae como consecuencia que no se puedan adaptar a las dinámica actuales del mercado.

En las empresas autogestionadas tiende a haber una separación entre los que administran y los que se encargan de la producción; es decir, entre los trabajadores especializados con los no especializado como en el caso de Argentina (Sodo \& Hudson, 2006) y Yugoslavia (Romero, 1994). Para resolver ello, es necesario que las empresas sean escuelas, en donde los trabajadores aprendan a hacer de todo para poder generar puestos rotativos y romper con esa división.

Entre los problemas encontrados en Yugoslavia está la gran autonomía de las repúblicas que hacía que hubieran desigualdades de rentas entre los países que lo formaba (Romero, 1994), la independencia que tenían las unidades productivas produjo un "patriotismo de empresa" que trajo como consecuencia que las ganancias de cada una de ellas sean libres del control del sector público y de la población ajena a los medios de producción (Gil, 2011).

Sobre esto último, Lebowithz señaló que los trabajadores de las empresas autogestionarias se preocupaban solamente por ellos, existía mucho egoísmo que se manifestó en la falta de solidaridad hacia la sociedad, lo que trajo como consecuencia la desigualdad económica y la división de los países que conformaban la República (Novaes, 2011).

Para resolver todos esos problemas se debe establecer un equilibrio de poderes en el país. En donde el Estado, la sociedad civil organizada (en donde se incluye a los sindicatos) y las empresas confluyan equilibradamente para el desarrollo. La conclusión es que ninguna de esas organizaciones tenga más poder que el otro, sino que se trabaje conjuntamente, en donde el gobierno termina siendo un modulador de este equilibrio de poderes. Además, de formar el capital social para la cohesión en la sociedad, y que nadie vele solamente por sus intereses individuales o de su grupo, sino de todos en general.

La educación es vital para la formación del capital social, por ejemplo, el anarquista Paco Palazón de Murcia -que por su posición política se asume que en su concepción del capital social no debería estar el Estado- cuenta cómo es que en el colegio les inculcaban la solidaridad y el apoyo mutuo, algo que fue vital para su accionar social en la actualidad (González, 2011), no por nada el socialista utópico Robert Owen consideraba a la educación como un requisito necesario para poder transformar a las personas con el fin de crear comunidades exitosas, siendo la escuela un medio esencial para ese objetivo (Hudson, 2010). 
Owen sabe muy bien esta idea porque cuando él fundó la comunidad New Harmony basada en una economía cooperativa en el sector agrícola, fue un fracaso justamente porque las personas no cooperaban unos con otros, sino que se crearon fracciones opuestas y habían muchas disputas (Armand, 1982).

La muestra del poder de la educación lo evidencia el padre José María Arizmendiarrieta, quien pudo inspirar la creación de la cooperativa más grande del mundo -Mondragóngracias al proceso de educación que promovió en base al valor de la cooperación (Altuna, Loyola , \& Pagalday, 2011).

También está el campamento de Sherif en 1954, donde un grupo de niños, en un primer momento, fue divido en dos y los hicieron competir unos con otros, lo que desencadenó que ambos grupos se odiaran; solo había hostilidad y enfrentamientos. En cambio, cuando se decidió que ambos equipos se unieran para que trabajen juntos con el objetivo en común de conseguir recursos que eran escasos, todos ellos se volvieron amigos porque comenzaron a ayudarse mutuamente (Muzafer Sherif, 1961). Una clara diferencia entre la educación competitiva con la cooperativa.

Ahora, así como el capital social genera beneficios también produce efectos negativos, por ejemplo, uno de ellos es la de la exclusión a nuevos miembros (Fukuyama, 1996), puede utilizarse para hacer el mal -para robar, matar, etc.- (Ostrom \& Ahn, 2003) e incluso afectar a los propios integrantes que se benefician de él (Portes, 1998). Sobre esto último, el autor mencionado (Portes, 1998) desarrolla tres puntos:

1. Reclamos excesivos a los integrantes del grupo: por ejemplo, cuando ciertos miembros comienzan a tener éxito económico, ciertos participantes exigen que ayuden a otros compañeros.

2. Restricciones a la libertad individual: cuando una persona del grupo obtiene beneficios, inmediatamente lo tiende a compartir, lo que genera que sea dificultoso para esta persona acumular stock, para hacerlo debe distanciarse de sus compañeros.

3. Normas niveladoras hacia abajo: cuando el éxito de una persona del grupo afecta la cohesión del conjunto, lo que se crean son normas que mantienen a todos los miembros iguales, por lo que genera que los que sean ambiciosos tengan que escaparse.

Sobre lo dicho por los autores se puede señalar que todos esos efectos negativos puede ser fácilmente solucionados; por ejemplo, el tema del rechazo a nuevos integrantes se soluciona en cuanto los propios miembros entiendan que justamente requieren de las redes interpersonales para conseguir más beneficios, por lo que restringir sus relaciones sería perjudicial para ellos mismo; el uso del capital social para hacer el mal se soluciona con las mismas reglas de la sociedad, el rechazo sobre esas prácticas va a restringir, y en el mejor de los casos eliminar, el uso de este tipo de capital para esos fines; y por último, en cuanto a los efectos negativos sobre los propios beneficiarios del capital social, estos se solucionan con reglas internas donde se promueva un equilibrio entre el éxito individual con el grupal.

En términos generales lo que se ha podido demostrar con la presente investigación es que sí es posible encontrar estructuras económicas que tienen al capital social como uno de sus elementos, caracterizado principalmente por valores como la confianza, cooperación, solidaridad y ayuda mutua. Cabe resaltar que, a pesar de las diferencias existentes en los distintos autores sobre el concepto de este tipo de capital, todos coinciden en que se trata de un recurso basado en las relaciones interpersonales que puede ser utilizado para obtener algún beneficio. 


\section{Referencias Bibliográficas}

Adler, P., \& Kwon, S. (2002). Social capital: prospects for a new concept. Academy of Management Review, 27(1), 17-40. DOI: 10.5465/AMR.2002.5922314

Altuna, L., Loyola , A., \& Pagalday, E. (2011). Mondragón: los dilemas de un cooperativismo maduro. En C. Piñeiro, Cooperativas y socialismo: una mirada desde Cuba (págs. 191-218). La Habana, Cuba: Editorial Caminos.

Armand, E. (1982). Historia de las experiencias de vida en común sin Estado ni autoridad. Madrid, España: Hacer.

Bacile, E., \& Ferreyra, Y. (2012). De la precariedad laboral a la productividad autogestionaria. Implicancias éticas y su vinculación con la Identidad Institucional. Gestión de las Personas y Tecnología, 4(15), 12-22.

Banco Mundial. (1989). Informe sobre el Desarrollo Mundial. Washington D. C., Estados Unidos: Banco Mundial.

Bastos, E. (1978). El sistema yugoslavo, ¿sistema comunal? Apuntes.Revista de Ciencias Sociales(8), 143-150. DOI: 10.21678/apuntes.8.549

Bazan, L., \& Schmitz, H. (1997). Social Capital and Export Growth: An Industrial Community in Southern Brazil. IDS Discussion Paper 361 Brighton: IDS.

Béjar, H. (2011). Justicia social, política social. Lima, Perú: Achebé ediciones.

Bermúdez-Figueroa, E., Serrano, J., \& Roca, B. (2019). El precio de la autonomía sindical durante la Transición española: el caso de la Unión Sindical Obrera en la provincia de Cádiz. Revista Tempo e Argumento, 11(27), 359-386. DOI: 10.5965/2175180311272019359

Bernecker, W. (1982). Colectividades y Revolución Social: el anarquismo en la guerra civil española, 1936 - 1939. Barcelona, España: Crítica.

Blacutt, M. (2013). El desarrollo local complementario (un manual para la Teoría en Acción). Texcoco, México: Eumed.

Botella, H. (2013). Capital social y pobreza en Ecuador, 2010-2012. Ánfora, 20(35), 93-115. DOI: 10.30854/anf.v20.n35.2013.45

Bottasso, J. (2004). La Pobreza no es Invencible. Pensamiento y praxis de Muhammad Yunus. Quito, Ecuador: Ediciones Parroquia Universitaria.

Bourdieu, P. (1985). The social space and the genesis of groups. Theory and Society, 14(6), 723-744. DOI: $10.1177 / 053901885024002001$

Bourdieu, P. (1986). The Forms of Capital. En J. Richardson, Handbook of Theory and Research for the Sociology of Education (págs. 241-258). New York, Estados Unidos: Greenwood Press.

Bourdieu, P. (1989). Social space and symbolic power. Sociological Theory, 7(1), 14-25. DOI: $10.2307 / 202060$

Buendía, L. (2002). La experiencia autogestionaria durante la Guerra Civil Española. Disponible en https://bit.ly/3yajHds

Cainelli, G., Mancinelli , S., \& Mazzanti, M. (2007). Social Capital and Innovation Dynamics in District-Based Local Systems. Journal of Socio- Economics, 36(6), 932-948. DOI: 10.1016/j. socec.2007.01.023

Capdevielle, J. (2014). Capital social: debates y reflexiones en torno a un concepto polémico. Revista de Sociologia e Política, 22(51), 3-14. DOI: 10.1590/1678-987314225101

Carrau, R. (2017). Capital social y cooperativismo. Lex Social: revista jurídica de los derechos sociales, 7(2), 179-204.

Casanueva, C., Castro , I., \& Galán, J. (2010). Capital social e innovación en clusters industriales. Revista Europea de Dirección y Economía de la Empresa, 19(4), 37-58.

Castillo, L. d. (2011). Los emprendimientos económicos locales y las formas alternativas de gestión de la propiedad estatal socialista. Economía y Desarrollo, 146(1-2), 42-61. 
Chang, H. -J. (2008). ¿Qué fue del buen samaritano? Naciones ricas, políticas pobres. Barcelona, España: Intermón Oxfam Editorial.

Chang, H.-J. (2015). Economía para el 99\% de la población. Barcelona, España: Penguin Random House Grupo Editorial.

Charles-Leija, H., Torres, A., \& Castro, D. (2018). Efectos del capital social en el empleo en México. Revista de Economía Institucional, 20(38), 263-283. DOI: 10.18601/01245996. v20n38.11

Chomsky, N. (26 de Abril de 2016). La hipocresía neolibera. (Y. Varoufakis, Entrevistador) Biblioteca Pública de Nueva York. Recuperado de https://www.youtube.com/watch?v=1wSNqs3ikU [Consultado el 4/septiembre/2020 ]

Cohen, D. (1998). Riqueza del mundo, pobreza de las naciones. Buenos Aires, Argentina: Fondo de Cultura Económica de Argentina.

Coleman, J. (1990). Commentary: Social institutions and social theory. American Sociological Review, 55(3), 333-339. DOI: 10.2307/2095759

Coleman, J. (1994). Foundations of Social Theory. Massachusetts, Estados Unidos: Harvard University Press.

Coraggio, J. (1999). Política social y economía del trabajo. Alternativas a la política neoliberal para la ciudad. Madrid, España: Miño y Dávila.

Coraggio, J. (2016). Movimientos sociales y economía. En J. Coraggio, Economía social y solidaria en movimiento (págs. 15-35). Los Polvorines, Argentina: Universidad Nacional de General Sarmiento.

Cornejo, C. (2005). Capital social, competitividad y pymes. Ekonomiaz, 2(59), 92-117.

Cosovschi, A. (2018). Pensar la crisis en la periferia. Las ciencias sociales en Serbia y Croacia durante la disolución de Yugoslavia (tesis Tesis de doctorado). Instituto de Altos Estudios Sociales. Buenos Aires. Universidad Nacional de General San Martín.

Cruz, J., \& Piñeiro, C. (2011). Una introducción a las cooperativas. En C. Piñeiro, Cooperativas y socialismo: una mirada desde Cuba (págs. 31-54). La Habana, Cuba: Editorial Caminos.

Das, R. (2004). Social capital and poverty of the wage-labour class: problems with the social capital theory. Transactions of the Institute of British Geographers, 29(1), 27-45. DOI: 10.1111/j.00202754.2004.00112.x

Diaz, S. (2015). Contenidos Políticos en la recuperación de empresas argentinas. Apuntes para una desmitificación. Athenea Digital. Revista de Pensamiento e Investigación Social, 3(15), 25-46. DOI: 10.5565/rev/athenea.1230

Dosi, G. (1988). Sources, Procedures, and Microeconomic Effects Of Innovation. Journal of Economic Literature, 26(3), 1120-1171.

Durston, J. (1999). Construyendo capital social comunitario. Revista de la CEPAL 69, 103-118.

Durston, J. (2000). ¿Qué es el capital social comunitario? (SERIE Políticas Sociales 38). Santiago de Chile: Naciones Unidas. CEPAL. División de Desarrollo Social.

Enrico, C. (2014). ¿Por qué existe pobreza en el Perú?: la falta de espacios vitales y su relación con el desempleo, el subempleo y la miseria. Lima, Perú: Editorial San Marcos.

Espinoza, V., Salas , E., \& Samaniego, A. (2019). Microcrédito y dimensiones de capital social en Ecuador. 593 Digital Publisher CEIT, 4(5-1), 49-57. DOI: 10.33386/593dp.2019.5-1.153

Flores, E., \& Yapuchura, A. (2016). Formación de clusters de productores de trucha y la articulación con el mercado objetivo en la región de Puno-Perú. COMUNIC@CCIÓN, 7(1), 38-48.

Fountain, J. (1997). Social Capital: A Key Enabler of Innovation in Science and Technology. Massachusetts, Estados Unidos: Research Programs, John F. Kennedy School of Government, Harvard University.

Frediani, R. (2011). Ensayo sobre el capital social. Actualidad Económica, 21(74), 19-26. 
Fukuyama, F. (1996). Trust: The Social Virtues and the Creation of Prosperity. Nueva York, Estados Unidos: Free Press Papersbacks.

Gambina, J., \& Roffinelli , G. (2011). La construcción de alternativas más allá del capital. En C. Piñeiro, Cooperativas y socialismo: una mirada desde Cuba (págs. 55-70). La Habana, Cuba: Editorial Caminos.

García-Valdecasas, J. (2011). Una definición estructural de capital social. REDES-Revista Hispana para el Análisis de Redes Sociales, 20(6), 132-160. DOI: 10.5565/rev/redes.411

Giddens, A. (1993). Emile Durkheim. Escritos selectos: introducción y selección de Anthony Giddens. Buenos Aires, Argentina: Edición Nueva Visión.

Giddens, A. (1999). La tercera vía: la renovación de la socialdemocracia. Madrid, España: Santillana Ediciones Generales, S.L.

Giddens, A. (2001). La tercera vía y sus críticos. Madrid, España: Grupo Santillana de Ediciones.

Giddens, A. (2006). La constitución de la sociedad: bases para la teoría de la estructuración. Buenos Aires, Argentina: Amorrortu editores.

Gil, I. (2011). Cooperativismo socialista y emancipación humana. El legado de Lenin. En C. Piñeiro, Cooperativas y socialismo: una mirada desde Cuba (págs. 103-131 ). La Habana, Cuba: Editorial Caminos.

Gil-Lacruz, M., \& Gil-Lacruz, A. (2006). Del capital humano al capital social: estrategias de prevención del consumo de alcohol. Revista Española de Drogodependencia, 3(1), 79-92.

González, C. (2011). Anarquistas de Ayer y de Hoy. De la identitad antifascista en la guerra civil española a la Memoria actual. Diacronie: Studi di Storia Contemporanea (documento 16) (7), 1-22. DOI: 10.4000/diacronie.3359

González-Seijo, A., Muñoz , R., \& Pons, R. (2014). Propuesta de políticas para la planificación de la actividad de ciencia, tecnología e innovación en centros de investigación de la Universidad Central Marta Abreu de Las Villas. Economía y Desarrollo, 152(2), 53-68.

Grameen Bank. (2019). Grameen. Obtenido de http://www.grameen.com/introduction/ [Fecha de consulta: 8/septiembre/2020]

Guerra, P. (2014). Socioeconomía de la solidaridad: una teoría para dar cuenta de las experiencias. Bogotá, Colombia: Ediciones Universidad Cooperativa de Colombia.

Halpern, D. (2005). Social capital. Londres: Polity.

Hanifan, L. (1916). The rural school community center. Annals of the American Academy of Political and Social Science, 67, 130-138. DOI: 10.1177/000271621606700118

Huber, L., \& Lamas, L. (2017). Deconstruyendo el Rombo: Consideraciones sobre la nueva clase media en el Perú. Lima, Perú: Instituto de Estudios Peruanos.

Hudson, J. (2010). Formulaciones teórico-conceptuales de la autogestión. Revista Mexicana de Sociología, 72(4), 571-597.

Huerta, J. (2017). ¿Es el capital social un tipo de capital? Un análisis desde el proceso de estratificación. Revista de El Colegio de San Luis(13), 92-129.

Iglesias, J. (2007). ¿Hay alternativas al capitalismo? La renta básica de los iguales. Revista Apuntes del CENES, 27(43), 131-156.

Jiménez, M., \& Piña, H. (2011). Capital social en empresas familiares. Revista Venezolana de Gerencia, 16(54), 255-273. DOI: 10.37960/revista.v16i54.10615

Klein, N. (2010). La doctrina del shock: El auge del capitalismo del desastre. Barcelona, España: Paidós

Kliksberg, B. (1999). Capital social y cultura, claves esenciales del desarrollo. Revista de la CEPAL 69, 85-102.

Knack, S. y. Keefer, P. (1997). Does social capital have an economic payoff? A cross country Investigation. Quarterly Journal of Economics, 112(4), 1251-1288. DOI: 10.1162/003355300555475 
Knight, P., \& Roca, S. (9 al 27 de junio de 1975). Sistemas de autogestión. Documento síntesis de las conclusiones del Taller sobre Implementación de Sistemas de Autogestión en Cornell University (págs. 1467-1481). New York, Estados Unidos: Cornell University.

Kogan, L. (2011). Aprender a Investigar. Lima, Perú: Fondo Editorial Universidad de Lima.

Kröpotkin, P. (2005). El apoyo mutuo. Un factor de evolución. Santiago, Chile: Instituto de Estudios Anarquistas.

Kuznets, S. (1960). Economic Growth Of Small Nations. En E. Robinson, Economic Consequences of the Size of Nations. International Economic Association Conference Volumes (págs. 14-32). Londres, Inglaterra: Palgrave Macmillan.

Lederman, L. (1987). Science and Technology Policies and Priorities: A Comparative Analysis. Science. Nuevas series, 237(4819), 1125-1133. DOI: 10.1126/science.237.4819.1125

Lelé, S. (1991). Sustainable Development: A Critical Review. World Development, 19(6), 607-621. DOI: 10.1016/0305-750X(91)90197-P

Lesser, E., \& Cothrel, J. (2001). Fast Friends: Virtuality and social capital. Knowledge Directions, 2(1), 66-79. DOI: 10.1093/0195165128.003.0002

Lida, C., \& Illades, C. (2001). El anarquismo europeo y sus primeras influencias en México después de la Comuna de París: 1871- 1881. Historia Mexicana, LI(1), 103-149.

Light, I. (1984). Immigrant and ethnic enterprise in North America. Ethnic and Racial Studies, 7:2, 195-216. DOI: 10.1080/01419870.1984.9993441

Light, I., \& Bonacich, E. (1988). Immigrant Entrepreneurs: Koreans in Los Angeles 1965- 1982. California, Estados Unidos: University of California Press.

Lipovetsky, G. (2010). La cultura-mundo: Respuesta a una sociedad desorientada. Barcelona, España: Editorial Anagrama.

Lobo, S., \& Eva, L. (2011). El capital social y la organización social para la producción. Actualidad Contable FACES, 14(23), 102-117.

López, M., Martín , F., \& Romero, P. (2007). Una revisión del concepto y evolución del capital social. En J. Ayala, Conocimiento, Innovación y Emprendedores: camino al futuro (págs. 1060-1073). La Rioja, España: Universidad de La Rioja.

Lundvall, B.-Å. (2002). Estado-nación, capital social y desarrollo económico. Un enfoque sistémico de la creación de conocimiento y el aprendizaje en la economía global. Revista de Economía Mundial(7), 69-90.

Lyon, F. (2000). Trust, Networks and Norms: The Creation of Social Capital in Agricultural Economies in Ghana. World Development, 28(4), 663-681. DOI: 10.1016/S0305-750X(99)00146-1

Machado, G. (2020). Cooperativismo de vivienda por ayuda mutua. Formación, experiencia y lucha en Uruguay. Revista de Ciencias Sociales, 33(47), 111-138. DOI: 10.26489/rvs.v33i47.6

Malhotra, N. (1997). Investigación de Mercados. Un Enfoque Práctico. México D. F., México: Prentice-Hall.

Marañón-Pimentel, B. (2012). La colonialidad del poder y la economía solidaria. Apuntes para la reflexión teórico-metodológica del Grupo de Trabajo Economía Solidaria, CLACSO. En B. Marañon-Pimentel, Solidaridad económica y potencialidades de transformación de América Latina. Una perspectiva descolonial (págs. 21-58). Buenos Aires, Argentina: Clacso.

Marín, J. C. (2014). El comunismo y la historia de Italia en el siglo XX (Tesis de fin de grado). Jaén, Andalucía: Universidad de Jaén.

Martínez-Cárdenas, R., Ayala-Gaytán , E., \& Aguayo-Téllez, E. (2015). Confianza y capital social: evidencia para México. Economía, Sociedad y Territorio, XV(47), 35-59.

Marx, C. (1994). El Capital tomo 1, vol II. México D. F., Méxio: Siglo XXI.

Mavares, A., Díaz, M., Colina, F., Lombardi , D., \& Prieto, J. (1999). El capital humano, el capital social y su importancia para el desarrollo económico. Revista de Ciencias Sociales FCES - LUZ Nueva Epoca, V(2), 129-136. DOI: 10.31876/rcs.v5i2.25055 
Meier, G., \& Stiglitz, J. (2002). Fronteras de la economía del desarrollo: El Futuro en Perspectiva. Bogotá, Colombia: Alfaomega Colombiana.

Mejía-Giraldo, A., Mendieta-Cardona, C., \& Bravo-Castillo, M. (2015). Estrategias de innovación y capital social en la pequeña y mediana empresa. Ingeniería Industrial, XXXVI(3), 286-296.

Méndez, N., \& Vallota, A. (2001). El anarquismo: una utopía que renace. Utopía y Praxis Latinoamericana, 6(15), 9-29.

Miranda, H. (2011). Cooperativismo y autogestión en las visiones de Marx, Engels y Lenin. En C. Piñeiro, Cooperativas y socialismo: una mirada desde Cuba (págs. 71-102). La Habana, Cuba: Editorial Caminos.

Mondragón. (2019). Somos Cooperación. Informe Anual 2019. País Vasco: Mondragón.

Morales, A. (2002). La construcción de capital social a través de la economía social: el caso Andaluz. REVESCO.Revista de Estudios Cooperativos(78), 89-119.

Moser, C. (1998). The Asset Vulnerability Framework: Reassessing Urban Poverty Reduction Strategies. World Development, 26(1), 1-19. DOI: 10.1016/S0305-750X(97)10015-8

Muzafer Sherif, O. J. (1961). Intergroup Conflict and Cooperation: The Robbers Cave Experiment. Oklahoma, Estados Unidos: Norman: University of Oklahoma Book Exchange.

Nahoum, B. (1984). El cooperativismo de ayuda mutua en el Uruguay: una alternativa popular y autogestionaria de solución al problema de la vivienda. Informes de la Construcción, 36(362), 1-14. DOI: 10.3989/ic.1984.v36.i362.1921

Napoli, P. N. (2018). Una mirada a las investigaciones cualitativas sobre jóvenes, conflictos y violencia en las escuelas secundarias de América Latina. EntreDiversidades. Revista de ciencias sociales y humanidades(10), 9-37. DOI: 10.31644/ED.10.2018.a01

Narayan, D., \& Pritchett , L. (1997). Cents and Sociability. Household Income and Social Capital in Rural Tanzania. Washington, D.C. Estados Unidos: Banco Mundial.

Navas, J. L. (1977). La cooperación clásica y el socialismo autogestionario yugoslavo. Análisis de sus analogías y diferencias. Estudios Cooperativos(41), 3-63.

Noguero, F. L. (2002). El análisis de contenido como método de investigación. XXI, Revista de Educación $N^{\circ}$ 4, 167-179.

North, D. (1990). Institutions, institutional change, and economic performance. Cambridge, Inglaterra: Cambridge University Press.

Nova, A. (2011). Las cooperativas agropecuarias en Cuba: 1959-presente. En C. Piñeiro, Cooperativas y socialismo: una mirada desde Cuba (págs. 321-336). La Habana, Cuba: Editorial Caminos.

Novaes, H. (2011). Las bases del socialismo autogestionario: la contribución de István Mészáros. En C. Piñeiro, Cooperativas y socialismo: una mirada desde Cuba (págs. 167190). La Habana, Cuba: Editorial Caminos.

Ojeda, R., Mul, J., López , L., \& Jiménez, O. (2010). Contribución del capital social en la microempresa rural. Revista Mexicana de Agronegocios, 27(XIV), 398-410. DOI: 10.22004/ ag.econ.93909

Ostrom, E., \& Ahn, T. (2003). Una perspectiva del capital social desde las ciencias sociales: capital social y acción colectiva. Revista Mexicana de Sociología, 65(1), 155-233. DOI: $10.2307 / 3541518$

Palma, I. (2015). Banco Diocesano de Alimentos Guadalajara como red social impelida por la carencia de alimento. Revista Espacios Transnacionales(4), 28-39.

Pérez, F., \& Fernández, J. (2006). Banca relacional y capital social en España. Competencia y confianza. Madrid, España: Fundación BBVA.

Pérez, J. (1996). Economía comunitaria y capital social. La cara oculta de la globalización en Centroamérica. Estudios sociológicos, XIV(41), 453-472.

Piñeiro, C. (2011). Prólogo. En C. Piñeiro, Cooperativas y socialismo: una mirada desde Cuba (págs. 7-30). La Habana, Cuba: Editorial Caminos. 
Piore, M., \& Sabel, C. (1984). The Second Industrial Divide: Possibilities for Prosperity. New York, Estados Unidos: Basic Books.

Pisani, E., \& Micheletti, S. (2018). Capital social y desarrollo rural: revisión de los aportes europeos en investigación aplicada. Pensamiento y Acción Interdisciplinaria, 4(2), 44-59. DOI: 10.29035/pai.4.2.44

Pisani, E., Franceschetti, G., Secco, L., \& Christoforou, A. (2017). Social capital and local development. Basingstoke, Inglaterra: Palgrave Editions.

Portela, M., \& Neira, I. (2002). Capital social: concepto y estudio econométrico sobre el capital social en España. Estudios Económicos de Desarrollo Internacional AEEADE, 2(2), 25-52.

Portes, A. (1998). Social capital: its origins and applications in modern sociology. Annual Review of Sociology, 24(1), 1-24. DOI: 10.1146/annurev.soc.24.1.1

Putnam, R., \& Feldstein, L. (2003). Better Together. Restoring the American Community. New York, Estados Unidos: Simon and Schuster.

Putnam, R., Leonardi, R., \& Nanetti, R. (1993). Making Democracy Work: Civic Traditions in Modern Italy. New Jersey, Estados Unidos: Princeton University Press.

Rey, G. (2007). Cultura, desarrollo y cooperación. Los reordenamientos de la agenda cultural. Quórum. Revista de pensamiento iberoamericano(17), 39-48.

Rivero, O. d. (1998). El mito del desarrollo: Los países inviables en el siglo XXI. Lima, Perú: Mosca Azul Editores.

Rodríguez, M., \& Ciolli, V. (2011). Tensiones entre el emprendedorismo y la autogestión: el papel de las políticas públicas en este recorrido. ORG \& DEMO (Marília), 12(1), 27-46. DOI: 10.36311/1519-0110.2011.v12n1.773

Rodríguez, M., \& Zapata, M. (2020). Organizaciones sociales y autogestión del hábitat en contextos urbanos neoliberales. Íconos. Revista de Ciencias Sociales, XXIV(67), 195-216. DOI: 10.17141/iconos.67.2020.3964

Rodríguez, N. (2019). La autogestión como resistencia, dos ejemplos en América Latina. Kavilando, 11(1), 119-139.

Rodríguez, P. (2012). Análisis relacional del capital social y el desarrollo de los sistemas productivos regionales. REDES-Revista Hispana para el Análisis de Redes Sociales, 23(9), 261-290. DOI: 10.5565/rev/redes.446

Romero, A. (1994). Yugoslavia: de las repúblicas de los consejos obreros a la guerra entre repúblicas. Papers, 44, 19-27. DOI: 10.5565/rev/papers.1743

Ruggeri, A. (2011). Autogestión obrera en Argentina: problemas y potencialidades del trabajo autogestionado en el contexto de la poscrisis neoliberal. En C. Piñeiro, Cooperativas y socialismo: una mirada desde Cuba (págs. 272-300). La Habana, Cuba: Editorial Caminos.

Ruiz, E. (2001). Introducción histórica a la filosofía del Estado (IV): la Comuna de París y la doctrina marxista del Estado. Filosofía, Política y Economía en el Laberinto(6), 7-21.

Rusque, A. (2005). Capacidad emprendedora y capital social. Revista Venezolana de Análisis de Coyuntura, XI(2), 189-202.

Sachs, J. (2006). El fin de la pobreza: Cómo conseguirlo en nuestro tiempo. Bogotá, Colombia: Random House Mondadori.

Sánchez, V. (2013). El capital social como instrumento del análisis económico. Cuadernos de Relaciones Laborales, 31(2), 473-493. DOI: 10.5209/rev_CRLA.2013.v31.n2.43227

Sanders, J., \& Nee, V. (1996). Immigrant Self-Employment: The Family as Social Capital and the Value of Human Capital. American Sociological Review, 61(2), 231-249. DOI: 10.2307/2096333

Schuldt, J. (2004). Bonanza macroeconómica y malestar microeconómica: apuntes para el estudio del caso peruano, 1988-2004. Lima, Perú: Universidad del Pacífico.

Schumacher, E. (1978). Lo pequeño es hermoso: Economía como si la gente importara. Madrid, España: Hermann Blume. 
Singer, P., \& Schiochet, V. (2016). La construcción de la economía solidaria como alternativa al capitalismo. En J. Coraggio, Economía social y solidaria en movimiento (págs. 87-100). Los Polvorines, Argentina: Universidad Nacional de General Sarmiento.

Sodo, J., \& Hudson, J. (2006). Comunicación social y trabajo. Posfordismo y autogestión fabril. La Trama de la Comunicación, 11, 241-255.

Stiglitz, J. (1998). Más instrumentos y metas más amplias: desde Washington hasta Santiago. Washington, D.C., Estados Unidos: Banco Mundial.

Stiglitz, J. (2015). La gran brecha: Qué hacer con las sociedades desiguales. Barcelona, España: Penguin Random House Grupo Editorial.

Suzzarini, A. (2010). Platón, origen de las utopias. Dikaiosyne: revista semestral de filosofía práctica(25), 145-160.

Talego, F. (1995). Cultura del Trabajo jornalera, discurso político y liderazgo: El caso del poder popular de Marinaleda. Revista de Antropología social(4), 131-151.

Tanaka, M. (1999). La participación social y política de los pobladores populares urbanos: ¿del movimientismo a una política de ciudadanos? El caso de El Agustino. Lima, Perú: Instituto de Estudios Peruanos.

Tocqueville, A. d. (1986). La democracia en América. San José, Costa Rica: Universidad Autónoma de Centro América.

Tokeshi, A. (2009). Tanomoshi, más que una simple "junta" de dinero. Una interpretación de la cultura solidaria okinawense en el Perú. Revista Electrónica Construyendo Nuestra Interculturalidad, 4(5), 1-8.

Urbina, D. A. (2015). Economía para herejes: desnudando los mitos de la economía ortodoxa. Washington, Estados Unidos: Amazon Edition.

Vargas, G. (2002). Hacia una teoría del capital social. Revista de Economía Institucional, 4(6), 71-108.

Vergara-Camus, L. (2011). Globalización, tierra, resistencia y autonomía: el EZLN y el MST. Revista Mexicana de Sociología, 3(73), 387-414. DOI: 10.22201/iis.01882503p.2011.3.28693

Vergara-Camus, L. (2016). Tomando el control: autonomía, subsistencia y desmercantilización. Gérmenes de otra economía en las luchas de los zapatistas en Chiapas y los sin tierra en Brasil. En J. Coraggio, Economía social y solidaria en movimiento (págs. 129-142). Los Polvorines, Argentina: Universidad Nacional de General Sarmiento.

Vicente, I. G. (2015). Autogestión socialista versus autogestión reformista. Filosofía, política y economía en el Laberinto(45), 25-39.

Woolcock, M. (1998). Social Capital and Economic Development: Toward a Theoretical Synthesis and Policy Framework. Theory and Society, 27(2), 151-208. DOI: 10.1023/A:1006884930135

Woolcock, M., \& Narayan, D. (2000). Social Capital: Implications for Development Theory, Research, and Policy. The World Bank Research Observer, 15(2), 225-249. DOI: 10.1093/wbro/15.2.225

Wyczykier, G. (2009). Sobre procesos de autogestión y recolectivización laboral en la Argentina actual. Polis, Revista de la Universidad Bolivariana, 8(24), 197-220. DOI: 10.4067/S071865682009000300011 